\title{
A probabilistic assessment of calcium carbonate export and dissolution in the modern ocean
}

\author{
Gianna Battaglia $^{1,2}$, Marco Steinacher ${ }^{1,2}$, and Fortunat Joos ${ }^{1,2}$ \\ ${ }^{1}$ Climate and Environmental Physics, Physics Institute, University of Bern, Bern, Switzerland \\ ${ }^{2}$ Oeschger Centre for Climate Change Research, University of Bern, Bern, Switzerland \\ Correspondence to: Gianna Battaglia (battaglia@climate.unibe.ch)
}

Received: 12 November 2015 - Published in Biogeosciences Discuss.: 21 December 2015

Revised: 20 April 2016 - Accepted: 21 April 2016 - Published: 13 May 2016

\begin{abstract}
The marine cycle of calcium carbonate $\left(\mathrm{CaCO}_{3}\right)$ is an important element of the carbon cycle and co-governs the distribution of carbon and alkalinity within the ocean. However, $\mathrm{CaCO}_{3}$ export fluxes and mechanisms governing $\mathrm{CaCO}_{3}$ dissolution are highly uncertain. We present an observationally constrained, probabilistic assessment of the global and regional $\mathrm{CaCO}_{3}$ budgets. Parameters governing pelagic $\mathrm{CaCO}_{3}$ export fluxes and dissolution rates are sampled using a Monte Carlo scheme to construct a 1000-member ensemble with the Bern3D ocean model. Ensemble results are constrained by comparing simulated and observation-based fields of excess dissolved calcium carbonate $\left(\mathrm{TA}^{*}\right)$. The minerals calcite and aragonite are modelled explicitly and ocean-sediment fluxes are considered. For local dissolution rates, either a strong or a weak dependency on $\mathrm{CaCO}_{3}$ saturation is assumed. In addition, there is the option to have saturation-independent dissolution above the saturation horizon. The median (and $68 \%$ confidence interval) of the constrained model ensemble for global biogenic $\mathrm{CaCO}_{3}$ export is $0.90(0.72-1.05) \mathrm{Gt} \mathrm{C} \mathrm{yr}^{-1}$, that is within the lower half of previously published estimates $(0.4-1.8 \mathrm{Gt}$

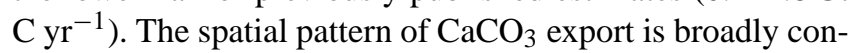
sistent with earlier assessments. Export is large in the Southern Ocean, the tropical Indo-Pacific, the northern Pacific and relatively small in the Atlantic. The constrained results are robust across a range of diapycnal mixing coefficients and, thus, ocean circulation strengths. Modelled ocean circulation and transport timescales for the different set-ups were further evaluated with CFC11 and radiocarbon observations. Parameters and mechanisms governing dissolution are hardly constrained by either the $\mathrm{TA}^{*}$ data or the current compilation of $\mathrm{CaCO}_{3}$ flux measurements such that model realisations
\end{abstract}

with and without saturation-dependent dissolution achieve skill. We suggest applying saturation-independent dissolution rates in Earth system models to minimise computational costs.

\section{Introduction}

The cycling of calcium carbonate $\left(\mathrm{CaCO}_{3}\right)$ forms an important component of the marine carbon cycle. It co-governs the surface-to-deep gradients of alkalinity and dissolved inorganic carbon (DIC) in the ocean (Volk and Hoffert, 1985), dominates deep ocean alkalinity fluxes, and influences the surface fields of DIC and alkalinity, thereby providing the background conditions for the uptake of excess anthropogenic carbon from the atmosphere. However, the export and dissolution fluxes of $\mathrm{CaCO}_{3}$ are highly uncertain. For example, current estimates of $\mathrm{CaCO}_{3}$ export diverge by a factor of $\sim 4\left(0.4-1.8 \mathrm{Gt} \mathrm{Cyr}^{-1}\right.$, summarised in Berelson et al., 2007).

The $\mathrm{CaCO}_{3}$ cycle is driven by calcifying organisms such as coccolithophorids, foraminifera, or pteropods, which remove calcium $\left(\mathrm{Ca}^{2+}\right)$, alkalinity, and DIC from the pelagic surface ocean waters to form shells and structures of $\mathrm{CaCO}_{3}$. These $\mathrm{CaCO}_{3}$ particles are eventually exported out of the surface, gravitationally sink through the water column, and dissolve at depth or get buried in ocean sediments. The formation and dissolution of $\mathrm{CaCO}_{3}$ introduces a vertical gradient in alkalinity and DIC. These gradients have been sustained against the counteracting forces of physical mixing and transport, which would otherwise have removed these gradients. This redistribution of alkalinity and carbon by bio- 
genic and physical transport affects the partitioning of carbon between the ocean and atmosphere and a reduction, expected under ongoing ocean acidification, or even a complete stop of $\mathrm{CaCO}_{3}$ export tend to decrease atmospheric $\mathrm{CO}_{2}$ by a few $\mathrm{ppm}$, and in the extreme case by up to $\sim 50 \mathrm{ppm}$, on century timescales (Heinze, 2004; Gangstøet al., 2011).

There are different mineral forms of $\mathrm{CaCO}_{3}$ and solubility is higher for high-magnesium calcite (typically present in fish) and aragonite (typically present in free-swimming pelagic sea snails and sea slugs; pteropods) than for calcite (typically present in calcifying algae; coccolithophorids). Thermodynamic considerations suggest that dissolution of $\mathrm{CaCO}_{3}$ particles occurs only when the product of the calcium and carbonate ion concentrations in the surrounding environment is below the saturation product. The saturation product of all minerals increases with increasing pressure (Mucci, 1983). At depth, respiration of organic matter additionally decreases the concentration of $\mathrm{CO}_{3}^{2-}$. As a result, the bulk of the water in the deep ocean is undersaturated with respect to $\mathrm{CaCO}_{3}$ minerals, generally enabling their dissolution, and oversaturated in the upper ocean, thermodynamically hindering their dissolution (Steinacher et al., 2009). Overall, the quantitative understanding of dissolution kinetics is, however, low and published estimates of saturationdependent dissolution kinetic parameters range over several orders of magnitude (summarised in Sarmiento and Gruber, 2006). $\mathrm{CaCO}_{3}$ dissolution may nevertheless still occur in the upper ocean in suitable, undersaturated microenvironments which would be present for instance in the guts of zooplankton, suspended organic aggregates, or fecal pellets (Bishop et al., 1980; Milliman et al., 1999; Jansen and Wolf-Gladrow, 2001). There are in fact several tracer-based studies reporting $\mathrm{CaCO}_{3}$ dissolution above the saturation horizon of bulk seawater (Barrett et al., 2014; Feely et al., 2002, 2004; Sabine et al., 2002b; Chung et al., 2003). In a modelling study, Friis et al. (2006), nevertheless, demonstrated that the method which is often employed to derive these upper ocean dissolution rates (Berelson et al., 2007, see Discussion section on $\mathrm{TA}^{*} \mathrm{CFC}$ age method), might not be applicable, because this method neglects physical transport and mixing of alkalinity. It is therefore still debated where and how fast settling $\mathrm{CaCO}_{3}$ particles are dissolved in the water column. Another complication, typically neglected in previous studies on open water $\mathrm{CaCO}_{3}$ dissolution, arises from ocean-sediment interactions and the influence of associated burial and redissolution fluxes on alkalinity and carbon concentrations in the open ocean (Archer, 1996).

Here we propose an alternative, probabilistic assessment of the global $\mathrm{CaCO}_{3}$ budget. We consider explicitly the transport and mixing of alkalinity and account for ocean-sediment interactions to probabilistically constrain the $\mathrm{CaCO}_{3}$ cycle with the observation-based distribution of the $\mathrm{TA}^{*}$ tracer. $\mathrm{TA}^{*}$ reflects the imprint of the $\mathrm{CaCO}_{3}$ cycle on alkalinity (see Sect. 2) and is therefore impacted by $\mathrm{CaCO}_{3}$ export, water column dissolution, physical transport, and mixing of the released alkalinity and DIC and ocean-sediment fluxes. For the probabilistic flux assessment, a large range of calcite and aragonite export and dissolution flux parameterisations are employed within our Earth system model of intermediate complexity (EMIC) - the Bern3D model - in a Monte Carlo set-up with 1000 members. The Bern3D model calculates the corresponding modelled steady-state tracer concentrations of TA*. The most probable export and dissolution fluxes are then the ones resulting in modelled TA* fields that match the observation-derived TA* distribution closely. The aim is to assign uncertainty estimates that will be consistent with both the observations and model equations - a classical data assimilation problem (see Sect. 3.3). It is expensive to perform simulations with interactive sediments (Heinze et al., 1999; Gehlen et al., 2006; Tschumi et al., 2011) due to long spin-up times required to bring ocean and sediments in equilibrium and we account a posteriori for the influence of sediment burial and dissolution fluxes on $\mathrm{TA}^{*}$ (see Sect. 3.3). This approach represents an alternative to the interpretation of concentrations without a physical model or the interpretation of flux/rate measurements within the water column, which are generally much sparser $(\sim 156$ flux measurements in the water column (Wilson et al., 2012) and $\sim 56$ benthic dissolution flux measurements (Berelson et al., 2007), globally) and more difficult to obtain. We apply the Wilson et al. (2012) data compilation of water column fluxes as an additional constraint for comparison. Additional sensitivity analyses with respect to vertical diffusion $\left(k_{\mathrm{dia}}\right.$, see Sect. 4) are illustrated. The results are compared and contrasted to databased estimates of export and dissolution (as summarised in Berelson et al., 2007). Finally, implications for the parameterisation of $\mathrm{CaCO}_{3}$ dissolution in Earth system models are discussed.

\section{Observation-derived TA*}

Total alkalinity data are from the GLODAP carbon climatology (Key et al., 2004) and salinity (Antonov et al., 2010), temperature (Locarnini et al., 2010), oxygen, and phosphate (Garcia et al., 2010a, b) data are from the World Ocean Atlas. These gridded data products represent objectively analysed climatological fields of the respective oceanic variables and are based on samples taken during the previous decades. They serve to split the alkalinity signal into its different physical and biogeochemical components such as $\mathrm{TA}^{*}$, our target variable in the data assimilation. We first regridded all required gridded data sets to the Bern3D model grid $(40 \times 41 \times 32$ grid boxes $)$ using the area-weighted regridding method of Ferret before deriving the other properties.

$\mathrm{TA}^{*}$, our target variable in the data assimilation, is a constructed tracer (Feely et al., 2002; Sabine et al., 2002a; Chung et al., 2003; Koeve et al., 2014) to exclusively capture the imprint of $\mathrm{CaCO}_{3}$ dissolution on alkalinity. $\mathrm{TA}^{*}$ is, in this sense, one of three components of measured total alkalinity 
Table 1. Overview of suggested ways of regression for $\mathrm{TA}^{0}$ either including two $(S, \mathrm{PO})$ or three $(S, \mathrm{PO}, T)$ explanatory variables and either as a global or basin-wide fit. The last column shows the root mean square error relative to the Global B3D estimate.

\begin{tabular}{|c|c|c|c|}
\hline & Equation (ueq kg ${ }^{-1}$ ) & $\begin{array}{l}\text { Mean } \\
\left(\mathrm{mol} \mathrm{m}^{-3}\right)\end{array}$ & $\begin{array}{l}\text { RMSE from Global } \\
\text { B3D }\left(\mathrm{mol} \mathrm{m}^{-3}\right)\end{array}$ \\
\hline Gruber et al. (1996): & $\mathrm{TA}^{0}=\left(367.5+59.9 \mathrm{psu}^{-1} \cdot S+0.074{\left.\mathrm{~kg} \mu \mathrm{mol}^{-1} \cdot \mathrm{PO}\right) \mu \mathrm{eq} \mathrm{kg}}^{-1}\right.$ & 2.377 & 0.012 \\
\hline Feely et al. (2002): & $\mathrm{TA}^{0}=148.7+61.36 \cdot S+0.0941 \cdot \mathrm{PO}-0.582 \cdot T_{\mathrm{pot}}$ & 2.39 & 0.0015 \\
\hline Friis et al. (2006): & as Feely et al. (2002) & & \\
\hline Global B3D 2V: & $\mathrm{TA}^{0}=\left(297.51+56.399 \mathrm{psu}^{-1} \cdot S+0.1259 \mathrm{~kg} \mathrm{umol}^{-1} \cdot \mathrm{PO}\right)$ ueq $\mathrm{kg}^{-1}$ & 2.387 & 0.0022 \\
\hline Global B3D: & $\mathrm{TA}^{0}=\left(345.64+56.03 \mathrm{psu}^{-1} \cdot S+0.069 \mathrm{~kg} \mathrm{umol}^{-1} \cdot \mathrm{PO}-0.9^{\circ} \mathrm{C}^{-1} \cdot T\right)$ ueq kg${ }^{-1}$ & 2.389 & 0 \\
\hline Regional B3D: & & 2.385 & 0.0047 \\
\hline Atlantic & $\mathrm{TA}^{0}=\left(688.15+44.97 \mathrm{psu}^{-1} \cdot S+0.129 \mathrm{~kg} \mathrm{umol}^{-1} \cdot \mathrm{PO}+1.34^{\circ} \mathrm{C}^{-1} \cdot T\right) \mathrm{ueqkg}^{-1}$ & & \\
\hline Pacific & $\mathrm{TA}^{0}=\left(381.05+55.26 \mathrm{psu}^{-1} \cdot S+, 0.049 \mathrm{~kg} \mathrm{umol}^{-1} \cdot \mathrm{PO}-1.20^{\circ} \mathrm{C}^{-1} \cdot T\right)$ ueq kg${ }^{-1}$ & & \\
\hline Indian & $\mathrm{TA}^{0}=\left(637.70+47.38 \mathrm{psu}^{-1} \cdot S+0.078 \mathrm{~kg} \mathrm{umol}^{-1} \cdot \mathrm{PO}-0.54^{\circ} \mathrm{C}^{-1} \cdot T\right) \mathrm{ueg} \mathrm{kg}^{-1}$ & & \\
\hline
\end{tabular}

(TA, Eq. (1), mean concentration $2.427 \mathrm{~mol} \mathrm{~m}^{-3}$ based on the regridded GLODAP data set). TA* can be extracted from TA by accounting for preformed $\left(\mathrm{TA}^{0}\right.$, Eq. 2$)$ and remineralised alkalinity (TA ${ }^{\mathrm{r}}$, Eq. 3):

$\mathrm{TA}=\mathrm{TA}^{0}+\mathrm{TA}^{\mathrm{r}}+\mathrm{TA}^{*}$.

$\mathrm{TA}^{0}$ is the background or preformed concentration, set at the ocean surface, and mixed conservatively in the ocean interior. Accordingly, $\mathrm{TA}^{\mathrm{r}}$ and $\mathrm{TA}^{*}$ are by definition zero in the surface ocean. To describe $\mathrm{TA}^{0}$ in the ocean interior, one relies on a multilinear regression relationship for surface ocean total alkalinity based on surface ocean salinity $(S)$ and $\mathrm{PO}\left(\mathrm{PO}=\mathrm{O}_{2}+r_{-\mathrm{O}_{2}}: \mathrm{PO}_{4} \cdot \mathrm{PO}_{4}, r_{-\mathrm{O}_{2}}: \mathrm{PO}_{4}=170\right.$, Broecker, $1974)$ and sometimes surface ocean temperature $(T)$ as explanatory variables (all conservative variables, see Eq. (2), Gruber et al., 1996; Sabine et al., 2002a; Feely et al., 2002).

$\mathrm{TA}^{0}=a_{0}+a_{1} \cdot S+a_{2} \cdot T+a_{3} \cdot \mathrm{PO}$

The coefficients, $a_{i}$, are estimated from observations of TA, $S, T$, and PO in the surface ocean. The linear regression fit is sometimes further subdivided to include only specific basins (Feely et al., 2002; Koeve et al., 2014). Table 1 summarises different regressions, including previously published regression estimates as well as new estimates by us calculated on the Bern3D model grid (B3D). The root mean squared errors (RMSEs) between these fits are smaller than $0.00465 \mathrm{~mol} \mathrm{~m}^{-3}$ (i.e. smaller than $0.2 \%$, excluding the Gruber et al. (1996) equation, which relies on an older database from 1996). From these different options, we accordingly chose the Global B3D linear regression including three explanatory variables and global data sets as ro- bust regression for $\mathrm{TA}^{0}$, which yields a mean concentration of $\sim 2.389 \mathrm{~mol} \mathrm{~m}^{-3}$

$\mathrm{TA}^{\mathrm{r}}$ is linked stoichiometrically to the apparent oxygen utilisation (AOU, Garcia et al., 2010b, Eq. 3) and accounts for decreases in TA due to the oxidation of organic nitrogen, phosphorous, and sulfur (OM).

$\mathrm{TA}^{\mathrm{r}}=r_{\mathrm{Alk}}: \mathrm{OM} \cdot r_{\mathrm{NO}_{3}}:-\mathrm{O}_{2} \cdot \mathrm{AOU}=1.26 \cdot 16 / 170 \cdot \mathrm{AOU}$

We set $r_{\text {Alk: OM }}$ to 1.26 (Kanamori and Ikegami, 1982) and $r_{\mathrm{NO}_{3}}: \mathrm{O}_{2}$ to $16 / 170$ (Anderson and Sarmiento, 1994) to uniformly, and globally link AOU changes to changes in TA (as in Feely et al., 2004; Koeve et al., 2014), which yields a mean concentration of $-18 \mathrm{mmol} \mathrm{m}^{-3}$. Wolf-Gladrow et al. (2007) propose an $8 \%$ higher value for $r_{\mathrm{Alk}}$ : OM of 1.36 , based on a different sulfur to carbon ratio. In addition, we note that AOU has been suggested to overestimate true oxygen utilisation by 20-25\% (Ito et al., 2004; Duteil et al., 2013). Accordingly, $\mathrm{TA}^{\mathrm{r}}$ might be associated with an uncertainty of $\sim 20 \%$

The remaining signal, then, is $\mathrm{TA}^{*}$ (mean concentration $\sim$ $57 \mathrm{mmol} \mathrm{m}^{-3}$ based on GLODAP and our reference choices to derive $\mathrm{TA}^{0}$ and $\mathrm{TA}^{\mathrm{r}}$ ), the changes in alkalinity due only to the $\mathrm{CaCO}_{3}$ cycle (Fig. 1). The global average RMSE of any of the described ways (16 in total) of accounting for $\mathrm{TA}^{\mathrm{r}}$ (25\% lower AOU or different $r_{\mathrm{Alk}}$ : OM) and $\mathrm{TA}^{0}$ (either two or three explanatory variables, and either global or regional) from our reference choices is $\sim 4 \mathrm{mmol} \mathrm{m}^{-3}$ (average RMSE 3.9, 3.8, $3.1 \mathrm{mmol} \mathrm{m}^{-3}$ in the Atlantic, Pacific, and Indian Ocean, respectively, i.e. $\sim 7 \%$ ). Note that this approach, inherent to its empirical nature, yields slightly negative $\mathrm{TA}^{*}$ values in some places. $\mathrm{TA}^{*}$ integrates to about $37.5 \mathrm{PmolC}$ or 75 Pmol Alk-equivalents of which $\sim 41 \%$ come to lie 


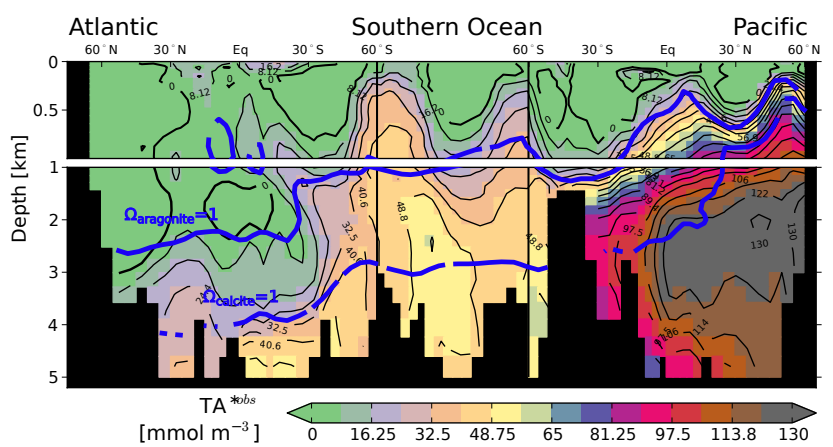

Figure 1. The $\mathrm{TA}^{*}$ tracer captures exclusively the influence of $\mathrm{CaCO}_{3}$ dissolution on alkalinity. An observationally based estimate of the $\mathrm{TA}^{*}$ distribution $\left(\mathrm{mmol} \mathrm{m}^{-3}\right)$ yielding an inventory of $\sim 37.5$ PmolC of which $\sim 41 \%$ comes to lie above the calcite saturation horizon. The calcite $\left(\sigma_{\text {calcite }}=1\right)$ and aragonite $\left(\sigma_{\text {aragonite }}=1\right)$ saturation horizon are shown by the blue lines. Displayed are results for a cross section through the Atlantic $\left(25^{\circ} \mathrm{W}\right)$, across the Southern Ocean $\left(58^{\circ} \mathrm{S}\right)$ into the Pacific, and through the Pacific $\left(175^{\circ} \mathrm{W}\right)$.

above the calcite saturation horizon (similar to Koeve et al. (2014) who find $44.7 \%$ of the TA* inventory above the calcite saturation horizon). These estimates are robust across the different sources of uncertainty. TA* concentrations are expressed in alkalinity equivalents throughout this paper and we do not divide $\mathrm{TA}^{*}$ concentrations by a factor of 2 as done in many observational studies which express $\mathrm{TA}^{*}$ in terms of carbon changes. $\mathrm{TA}^{*}$ inventories are in PmolC, and $\mathrm{CaCO}_{3}$ fluxes are given in carbon units $\left(\mathrm{Gt} \mathrm{Cyr}^{-1}\right.$, mmol $\left.\mathrm{Cm}^{-3} \mathrm{yr}^{-1}, \mathrm{mmol} \mathrm{Cm}^{-2} \mathrm{yr}^{-1}\right)$.

\section{The modelling framework}

To constrain the alkalinity fluxes associated with $\mathrm{CaCO}_{3}$ cycling, we introduce different export and dissolution fluxes (with a total of 15 degrees of freedom) within the biogeochemistry component of the Bern3D dynamic ocean model. The parameters of the new formulations describing the export and dissolution fluxes of $\mathrm{CaCO}_{3}$ are varied using a Monte Carlo sampling method (McKay et al., 1979; Steinacher et al., 2013) and the resulting model ensemble, including 1000 members, is run to a pre-industrial steady state, producing a broad range of solutions (see Sect. 3.2). The alkalinity fluxes associated with the $\mathrm{CaCO}_{3}$ cycle are then constrained by comparing observation-based and simulated $\mathrm{TA}^{*}$ data using a Bayesian approach following Steinacher et al. (2013); a skill score is assigned to each ensemble member and used as a weight for the computation of median values and probability density functions from the ensemble results. The sediment module is not included in the ensemble due to extensive computational cost $(\sim 150$ vs. $\sim 8$ CPUh for a single-member run with and without the sediment, respectively). Instead, we reran the model configurations which achieved the best skill scores with interactive sediments to account for $\mathrm{CaCO}_{3}$ burial and sediment redissolution a posteriori (see Sect. 3.3.3).

\subsection{The Bern3D model}

The Bern3D model couples a dynamic ocean, sea ice, an energy-moisture balance atmosphere, a marine biogeochemical cycle, a dynamic global vegetation model, and an ocean sediment module. Here an ocean version with a horizontal resolution of 41 by 40 grid cells and 32 logarithmically scaled vertical layers is used (see also Roth et al., 2014). The horizontal resolution is the same for the components atmosphere, ocean, sea ice, and sediments of the Bern3D model. Transport and mixing of tracers in the ocean is based on Edwards et al. (1998) and Müller et al. (2006) as a threedimensional frictional geostrophic model. The model has an isopycnal diffusion scheme and Gent-McWilliams parameterisation for eddy-induced transport (Griffies, 1998). The NCEP/NCAR monthly wind-stress climatology (Kalnay et al., 1996) is prescribed at the surface. Air-sea gas exchange for $\mathrm{CO}_{2}$ is implemented according to OCMIP-2 protocols (Najjar et al., 1999; Orr and Najjar, 1999). The global mean air-sea transfer rate is reduced by $19 \%$ compared to OCMIP-2 to match observation-based estimates of natural and bomb-produced radiocarbon (Müller et al., 2008). A two-dimensional energy moisture balance model represents the atmosphere (Ritz et al., 2011). The model is spun up to equilibrium under preindustrial conditions, with atmospheric $\mathrm{CO}_{2}$ set to $278 \mathrm{ppm}$. The spin-up period is 4000 years without the sediment module and 50000 years with the sediment module. Remaining model drifts are negligible. The last year of the spin-up period is considered for all analyses (note that unforced interannual variability is generally negligible in our model). We implicitly neglect potential changes in $\mathrm{TA}^{*}$ over the industrial period by comparing model results for preindustrial conditions with $\mathrm{TA}^{*}$ data reconstructed from recent measurements. Such changes are negligible in simulations with prescribed anthropogenic forcing in the Bern3D model.

The marine biogeochemical module computes the cycling of carbon, alkalinity, phosphate, iron, oxygen, silica, and carbon isotopes. New production of organic material in the model is limited by temperature, light, phosphate, and iron following Doney et al. (2006) as described by Parekh et al. (2008) and Tschumi et al. (2011). One-third (33\%) of the new production is exported out of the euphotic zone (defined at $75 \mathrm{~m}$ ) as particulate organic matter (POM), with the remainder contributing to the dissolved organic matter pool. Within biogeochemically similar regions, a parameter termed rain ratio linearly scales the pattern of POM export to $\mathrm{CaCO}_{3}$ export (silica limitation is not considered here). We define eight such regions, each assigned an independent value for the export rain-ratio parameter (mol inorganic carbon/mol organic carbon exported, later given in \% inorganic to organic carbon exported). These include the Pacific, Atlantic, 
and Indian sections of the Southern Ocean $\left(<35^{\circ} \mathrm{S}\right.$, separated at $240^{\circ} \mathrm{W}, 63^{\circ} \mathrm{W}$ and $\left.30^{\circ} \mathrm{E}\right)$, the tropical $\left(35^{\circ} \mathrm{S}\right.$ to $\left.30^{\circ} \mathrm{N}\right)$ Pacific, Atlantic, and Indian Ocean, and the northern $\left(>30^{\circ} \mathrm{N}\right)$ Atlantic (including the Arctic) and Pacific Ocean. A global parameter $\left(f_{\text {calc }}\right)$ determines how much of the total $\mathrm{CaCO}_{3}$ export flux represents calcite and how much represents aragonite $\left(1-f_{\text {calc }}\right)$. Abiotic $\mathrm{CaCO}_{3}$ precipitation is virtually absent in today's ocean and not considered (reviewed in Sarmiento and Gruber, 2006).

In the model, we implemented TA* as an explicit, idealised tracer (Koeve et al., 2014). It captures the alkalinity equivalents of $\mathrm{CaCO}_{3}$ dissolution whenever it occurs and mixes this signal, accordingly. TA* values are set to zero throughout the surface ocean.

In sensitivity simulations with the sediment module enabled, the flux of $\mathrm{CaCO}_{3}$, and of other particles, reaching the seafloor is passed to the sediment module from where a fraction potentially redissolves back into the water column. In simulations without the sediment module, the entire flux reaching the ocean floor redissolves back into the water column. Simulated TA* concentrations tend to be lower with the sediment module enabled than without the sediment module, because a fraction of the $\mathrm{CaCO}_{3}$ export flux is removed from the ocean and buried in the geosphere. The sediment diagenesis model (Heinze et al., 1999; Gehlen et al., 2006; Tschumi et al., 2011) features the same horizontal resolution as the ocean model and 10 layers resolving the top $10 \mathrm{~cm}$ of the seafloor. It dynamically calculates the transport, remineralisation/redissolution, and bioturbation of solid material within the top $10 \mathrm{~cm}$ of the seafloor as well as porewater chemistry and diffusion as described in detail in Tschumi et al. (2011). Solutes diffuse over a boundary layer of $1 \mathrm{~cm}$ between the sediment column and the lowermost ocean grid cell. Four solid components $\left(\mathrm{CaCO}_{3}\right.$, opal, POM, and clay) and pore water substances (carbon and carbon isotopes, total alkalinity, phosphate, nitrate, oxygen, and silicic acid) are modelled. The pore water carbonate ion concentration determines whether, and at which rate, $\mathrm{CaCO}_{3}$ dissolves. Aragonite and calcite are not distinguished within the sediment module and $\mathrm{CaCO}_{3}$ is assumed to be in the form of calcite. Any solid material that is pushed out of the diagenetic zone disappears into the subjacent diagenetically consolidated zone. During the spin up of the ocean-sediment model, the net loss of alkalinity, and other tracers such as carbon and nutrients, to the sediments is immediately replaced by corresponding riverine inputs which are distributed uniformly along the coastlines (and then taken to be part of $\mathrm{TA}^{0}$ ). The riverine input is diagnosed at the end of the spin up.

The model features the main water masses and mixing timescales of the ocean, an essential prerequisite to realistically simulate $\mathrm{TA}^{*}$ and other tracers. The simulated and observed distributions of the ventilation tracers $\Delta^{14} \mathrm{C}$ and CFC11 are provided in the Appendix along with a Taylor diagram (Taylor, 2001) of CFC11, $\Delta^{14} \mathrm{C}$, temperature, salinity, DIC, TA, $\mathrm{PO}_{4}$, oxygen, and TA* (Figs. A1 to A3). Glob- ally, the correlation coefficient and standard deviation of the median relative to the standard deviation of the observations

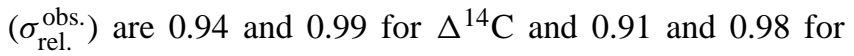
CFC11.

\section{2 $\mathrm{CaCO}_{3}$ dissolution within the water column}

The dissolution equations for calcite and aragonite are implemented using equations with identical functional forms, but with different parameters for each mineral. In the following, we do not explicitly distinguish the two minerals to ease notation. The dissolution of calcite and aragonite below the euphotic zone is assumed to be a function of the saturation state of the bulk seawater, $\Omega$, and the particle concentration per unit of water volume, $\left[\mathrm{CaCO}_{3}\right]$ (see Gangstøet al. (2011) for a discussion):

$\frac{\mathrm{d}\left[\mathrm{CaCO}_{3}\right]}{\mathrm{d} t}=-k_{\mathrm{eff}}(\Omega) \times\left[\mathrm{CaCO}_{3}\right]$.

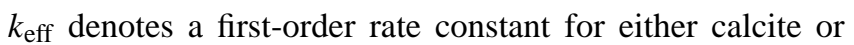
aragonite. It is defined as

$k_{\mathrm{eff}}(\Omega)=k_{0} \times(1-\Omega)^{n} \times H(\Omega-1)+k_{\mathrm{bg}}$.

$k_{0}$ and $k_{\mathrm{bg}}$ are rates in units of $1 /$ time. $H$ is the Heaviside function, which is zero for supersaturated and 1 for undersaturated water. The saturation state is defined by the ratio of the product of calcium ion concentration times carbonate ion concentrations to the saturation product, $K_{\mathrm{sp}}$ (Mucci, 1983):

$\Omega=\frac{\left[\mathrm{Ca}^{2+}\right]\left[\mathrm{CO}_{3}^{2-}\right]}{K_{\mathrm{sp}}}$.

$\Omega$ values larger than 1 correspond to oversaturated and $\Omega$ values smaller than 1 to undersaturated conditions. $\Omega$ and thus $k_{\text {eff }}$ are grid-cell-specific. At supersaturation, the dissolution rate $k_{\text {eff }}$ equals the constant background rate $k_{\text {bg }}$ (which can be zero). With increasing undersaturation, the dissolution rate increases towards its maximum value $\left(k_{\mathrm{bg}}+k_{0}\right) . n$ is a unitless parameter and determines the deviation from linearity of this increase. For simplicity and to avoid the addition of further free parameters, a constant sinking velocity, $v$, is assumed and identical for both calcite and aragonite particles. The flux profile of $\mathrm{CaCO}_{3}$ then takes the form

$F_{i, j}\left(z_{k}\right)=F_{i, j}\left(z_{k-1}\right) \cdot \exp \left(\frac{-k_{\mathrm{eff}}\left(\Omega_{i, j, k}\right)}{v} \cdot \Delta z_{k}\right)$,

where $F$ is the downward flux of either calcite or aragonite particles per unit area evaluated at the bottom of each tracer grid cell at depth $z_{k} . i, j$, and $k$ are grid cell indices indicating longitude, latitude, and depth. $\Delta z_{k}$ denotes grid cell height. The export flux is set equal to $F(z=75 \mathrm{~m})$ at the depth of the euphotic zone. Particles are dissolved instantaneously and sinking is not explicitly resolved in this formulation, reducing computational costs. $v / k_{\text {eff }}$ is in units of $\mathrm{m}$, 

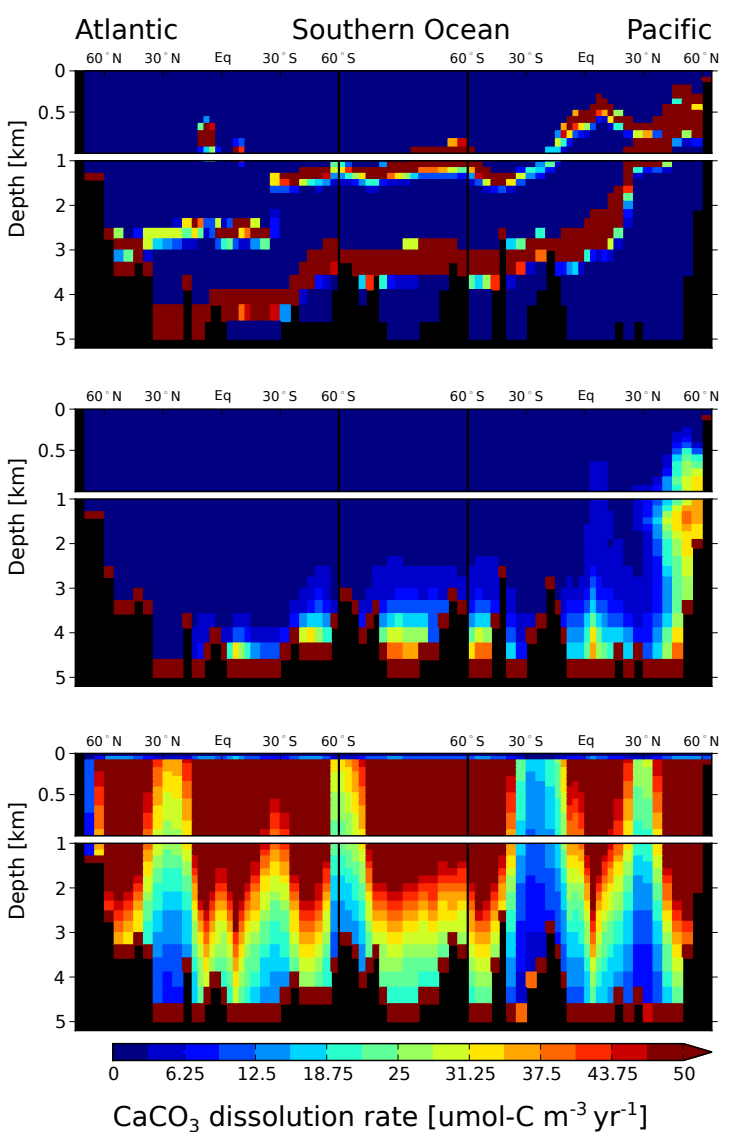
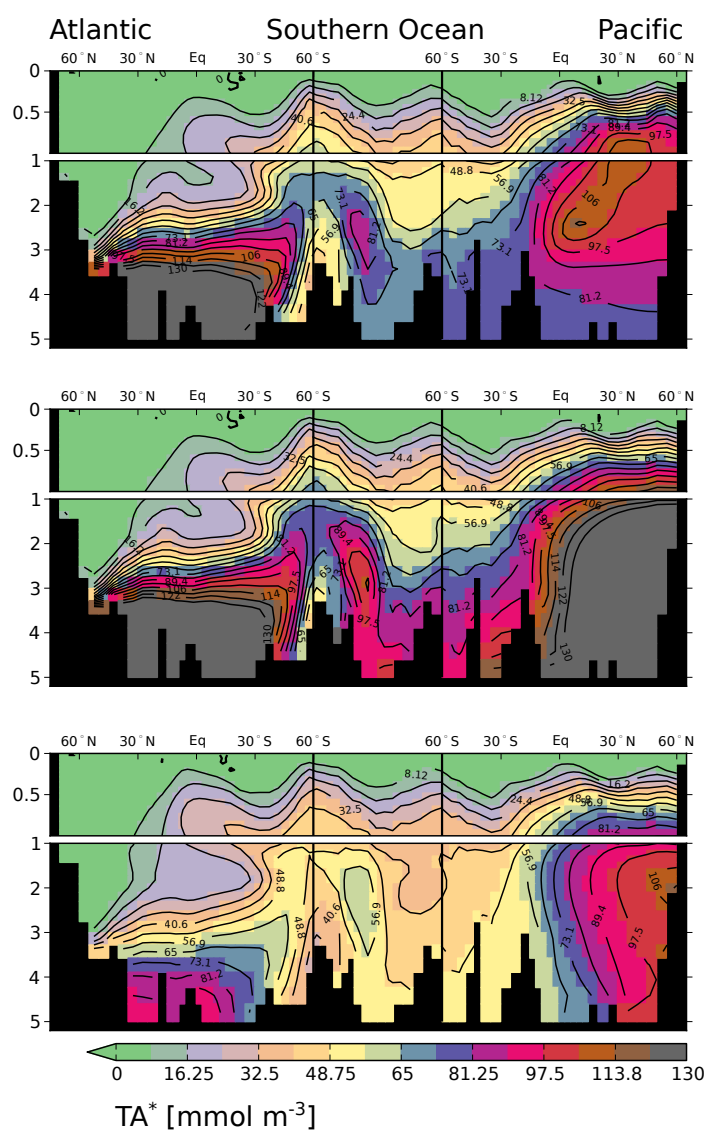

Figure 2. Results from sensitivity simulations applying three different illustrative dissolution schemes. Left column: $\mathrm{CaCO}_{3}$ dissolution rates. Right column: the resulting steady-state $\mathrm{TA}^{*}$ for these three contrasting parameterisations of the $\mathrm{CaCO}_{3}$ dissolution rate. The dissolution rate is set to increase fast (top row), slowly (middle row) with undersaturation of $\mathrm{CaCO}_{3}$, or is set constant throughout the water column (bottom row). The standard version of the Bern3D model without the sediment module is applied, and the fraction of $\mathrm{CaCO}_{3}$ export in the form of aragonite is set to $10 \%$. At least $43 \%$ of the dissolution signal is simulated above the calcite saturation horizon irrespective of whether dissolution is allowed to occur above the saturation horizon (bottom row) or not (middle and top row). This points to the importance of physical transport in shaping the distribution of $\mathrm{TA}^{*}$.

and, if assumed constant, can be interpreted as the dissolution length scale, i.e. the depth at which the flux has decreased to $1 / e$ (to $\sim 37 \%$ ) of the export flux at $75 \mathrm{~m}$. Any particles reaching the sea floor are dissolved completely in the appropriate lowermost box, except when the sediment module is included.

In Fig. 2 we illustrate three dissolution cases to explore the sensitivity of $\mathrm{TA}^{*}$ to dissolution profiles which cover the sampled uncertainty in dissolution rate parameters. The three dissolution rate profiles are selected to represent a case with constant, saturation-independent dissolution (constant) and two cases where this background dissolution rate is set to zero and $\mathrm{CaCO}_{3}$ dissolves only below the saturation horizon. In the fast (slow) case, aragonite (chosen to represent $10 \%$ of the total) and calcite (90\% of total export) dissolves quickly (slowly) below the saturation horizon. Aragonite and calcite dissolve within a few hundred metres below the saturation horizon in the fast case, while most $\mathrm{CaCO}_{3}$ dissolves on the ocean floor in the slow case.

The choice of the dissolution rate profile has a substantial influence on the simulated TA* inventory (Fig. 2, Table 2 , middle column, $k_{\text {dia, ref }}$ ). The global TA* inventory is $38 \mathrm{PmolC}$ for the case with a constant, saturationindependent dissolution and a rain ratio of $\sim 7 \%$, which is close to the observation-derived inventory of $37 \mathrm{PmolC}$. The simulated inventory is 48 and $63 \mathrm{PmolC}$ for the fast and slow cases (where no dissolution occurs above the saturation horizon), respectively, and by that substantially higher. $\mathrm{TA}^{*}$ accumulates in the deep ocean when all $\mathrm{CaCO}_{3}$ is dissolved below the saturation horizon of aragonite and calcite and no dissolution is permitted above. The TA* inventory and concentrations are sensitive to the choice of the dissolution rate profile, supporting our choice of $\mathrm{TA}^{*}$ as a target variable to constrain dissolution rates. 
Table 2. Results from sensitivity simulations. $\mathrm{CaCO}_{3}$ export and $\mathrm{TA}^{*}$ inventories for different physical mixing (diapycnal mixing coefficient, $k_{\text {dia }}$ ) and $\mathrm{CaCO}_{3}$ dissolution schemes. For these illustrative simulations, calcite and aragonite particles were assigned equal parameter values and $10 \%$ of export is assumed to be in the form of aragonite. Fast: $k_{0}=10 \mathrm{day}^{-1}, n=1, f_{\text {calc }}=0.9, k_{\mathrm{bg}}=0 ;$ slow: $k_{0}=0.16$ day ${ }^{-1}, n=2$, $f_{\text {calc }}=0.9, k_{\text {bg }}=0$; constant: $k_{\mathrm{bg}} / v=1 / 2900 \mathrm{~m}^{-1}$.

\begin{tabular}{llll}
\hline & $\begin{array}{l}k_{\text {dia, low }} \\
0.1 \times 10^{-4} \mathrm{~m}^{2} \mathrm{~s}^{-1}\end{array}$ & $\begin{array}{l}k_{\text {dia, ref }} \\
0.2 \times 10^{-4} \mathrm{~m}^{2} \mathrm{~s}^{-1}\end{array}$ & $\begin{array}{l}k_{\text {dia, high }} \\
0.5 \times 10^{-4} \mathrm{~m}^{2} \mathrm{~s}^{-1}\end{array}$ \\
\hline $\begin{array}{l}\text { Export at } 75 \mathrm{~m}\left(\mathrm{Gt} \mathrm{C} \mathrm{yr}^{-1}\right) \\
\text { TA* inventory (Pmol C) } \\
\left.\text { fraction of which lies above } \Omega_{\text {calc }}=1\right)\end{array}$ & 0.73 & 0.82 & 1.07 \\
Fast & $47.8(54 \%)$ & $47.9(52 \%)$ & $44.5(51 \%)$ \\
Slow & $62.5(45 \%)$ & $63.0(44 \%)$ & $58.9(43 \%)$ \\
Constant & $38.1(52 \%)$ & $38.4(51 \%)$ & $35.4(50 \%)$ \\
\hline
\end{tabular}

\subsection{Ensemble simulations and metrics for skill assessment}

\subsubsection{The Monte Carlo ensemble}

Following Steinacher et al. (2013) and Steinacher and Joos (2016) we run a 1000-member Latin hypercube ensemble to constrain the export flux out of the surface ocean, and the dissolution of aragonite and calcite within the water column. Latin hypercube sampling (McKay et al., 1979) is a statistical, Monte Carlo method to generate controlled random samples from a multidimensional distribution (15 dimensions in our case). The defined parameter ranges are divided into equally probable intervals (1000 in our case). Random samples are then generated in each interval. This method ensures that the sampled values are representative of the real variability, while minimising the number of required samples and thus the computational costs. We sample 15 parameters and apply uniform priors based on literature information. The free parameters are the eight rain-ratio parameters (prior range: 0 to $18 \%$ for the Pacific and South Indian regions, prior range: 0 to $16 \%$ for the tropical Indian, prior range: 0 to $7 \%$ for the North and tropical Atlantic, and prior range: 0 to $10 \%$ for the South Atlantic), defining the total amount of $\mathrm{CaCO}_{3}$ export for each of the six regions. The prior ranges of the rain ratios for the three Atlantic regions are limited to maximal $10 \%$. This selection is based on results from previous ensemble set-ups that revealed an overestimation of $\mathrm{TA}^{*}$ for high rain ratios in the Atlantic domain. Further we include the fraction $f_{\text {calc }}(1-0.5)$ defining the split between aragonite and calcite export, and $3 \times 2$ parameters governing the dissolution kinetics for calcite and aragonite, respectively. These are $k_{0}\left(0.05-10 \mathrm{day}^{-1}\right)$ and $n(1-4)$, describing fast and slow dissolution kinetics as a function of undersaturation, and $k_{\mathrm{bg}} / v\left(0-1 / 2500 \mathrm{~m}^{-1}\right)$, the length scale associated with a constant, background dissolution rate acting both above and below the saturation horizon. $v$ is kept constant at 100 mday $^{-1}$.

The observation-based saturation state of the bulk seawater with respect to aragonite and calcite is prescribed for each model grid cell. It was calculated with the carbonate chemistry package seacarb (Gattuso et al., 2010) from GLODAP (Key et al., 2004) and World Ocean Atlas 2009 (WOA09; Locarnini et al., 2010; Antonov et al., 2010). Seacarb calculates carbonate chemistry based on pressure, temperature, salinity, alkalinity, DIC, silica, and phosphate. This reduces computational costs as the carbonate chemistry package of the online model requires substantial computational time. In addition, this avoids mismatches in the modelled and observation-based saturation states, which are also due to model deficiencies in the cycling of organic matter and physical transport. Mismatches in modelled and observed saturation states are particularly large in the North Pacific, where the modelled calcite saturation horizon is up to $1.5 \mathrm{~km}$ too deep. The calcite saturation horizon is well represented in the South Pacific, Indian and Atlantic by the model. The results presented in Sect. 4 suggest that estimated $\mathrm{CaCO}_{3}$ export production fields and dissolution rates are insensitive to the choice of the saturation field, because saturation-dependent and saturation-independent parameterisations of dissolution yield similar TA* fields.

\subsubsection{Skill scores}

Global skill scores, $S_{m}$, are assigned to each member, $m$, of the Latin hypercube ensemble:

$S_{m}=\exp \left(-0.5 \cdot \mathrm{MSE}^{\mathrm{rel}}\right)$.

$\mathrm{MSE}^{\text {rel }}$ is the relative mean squared error of the simulated $\mathrm{TA}^{*}$ concentrations from member $m$ with respect to observation-derived $\mathrm{TA}^{*}$ :

$\mathrm{MSE}^{\mathrm{rel}}=\sum_{j} a_{j} \times \frac{\left(\mathrm{TA}_{j}^{* \text { model }}-\mathrm{TA}_{j}^{* \mathrm{obs}}-\mathrm{TA}_{j}^{* \text { sedcorr }}\right)^{2}}{\sigma^{2}}$.

The sum includes all grid cells (indexed $j$ ). TA ${ }_{j}^{* \text { model }}$ denotes simulated $\mathrm{TA}^{*}$ concentrations for ensemble member $m$ and $\mathrm{TA}_{j}^{* \mathrm{obs}}$ observation-based $\mathrm{TA}^{*}$ concentrations estimated by 
using the Global B3D regression (Sect. 2). TA ${ }_{j}^{* s e d c o r r}$ is a correction term arising from $\mathrm{CaCO}_{3}$ burial in sediments, further explained below. $a_{j}$ is the grid cell volume used as weight in the sum. $\sigma^{2}$ represents the combined error of the observationbased $\mathrm{TA}^{*}$ estimates and of the model and sets the scale against which model deviations are evaluated. Model deviations from the observations are considered large or small relative to the magnitude of $\sigma^{2}$ (Schmittner et al., 2009). The total uncertainty in observation-derived gridded $\mathrm{TA}^{*}$ data is difficult to estimate and includes uncertainties due to extrapolation of limited number of measurements, uncertainties in individual tracer measurements, and in the computation of $\mathrm{TA}^{*}$ from tracer data. The error associated with the procedure to compute TA* (average RMSE 3.9, 3.8, $3.1 \mathrm{mmol} \mathrm{m}^{-3}$ in the Atlantic, Pacific, and Indian Ocean, respectively; see Sect. 2) is small compared to the model error (the best run achieves a RMSE of 11,18 , and $18 \mathrm{mmol} \mathrm{m}^{-3}$ in the Atlantic, Pacific, and Indian Ocean, respectively). Following Steinacher et al. (2013) and Schmittner et al. (2009), we estimate $\sigma^{2}$ as the (volume-weighted) variance of the modeldata discrepancy for the ensemble member with the lowest MSE (this variance is $\left.275\left(\mathrm{mmol} \mathrm{m}^{-3}\right)^{2}\right)$; this corresponds to MSE $^{\text {rel }}$ close to unity for the best-fitting ensemble member.

The skill scores $S_{m}$ of the individual ensemble members are likelihood-type functions corresponding to a Gaussian distribution of the data-model discrepancy $\left(\mathrm{TA}^{* \text { model }}-\right.$ $\mathrm{TA}^{* \mathrm{obs}}-\mathrm{TA}^{* \text { sedcorr }}$ ) with zero mean and variance $\sigma^{2} . S_{m}$ is an indication of the relative performance/credibility of each individual model configuration. Configurations which have relatively small deviations from the data are judged more probable than configurations which differ greatly from the observations.

$S_{m}$ are used as weight to compute probability density functions (PDFs) and related measures such as the median (50th percentile) and the 16 and 84th percentiles defining the one standard deviation confidence interval $(1 \sigma)$ of the ensemble results. PDFs represent weighted and normalised histograms of the variables of interest. The normalisation is such that the integral over a PDF equals 1 . A cubic spline interpolation is used to arrive at a continuous PDF from the discrete, normalised histogram. For the computation of median and confidence ranges the histograms are converted to cumulative distribution functions (CDFs). We interpolate linearly within the discrete CDFs to arrive at the chosen percentiles (i.e. $\mathrm{CDF}=(0.16,0.5,0.68))$.

The above explanations apply to any simulated quantity of interest. In the following we will present PDFs, median values, and $1 \sigma$ confidence ranges for aragonite and calcite export and dissolution as well as for tracer concentrations at individual grid cells or integrated over regions or the whole ocean. Spatial integrations are done for each ensemble member individually and before computing the PDFs and associated measures from the full ensemble.
Table 3. Mean sediment burial fluxes $\left(\mathrm{Gt} \mathrm{Cyr}^{-1}\right)$ and observationbased vs. simulated $\mathrm{TA}^{*}$ inventories $(\mathrm{PmolC})$. $\mathrm{TA}^{* \text { sedcorr }}$ is estimated as the mean difference in $\mathrm{TA}^{*}$ between runs with and runs without the sediment module across the 14 best Bern3D simulations. The median estimate is from the constrained 1000-member ensemble (without the sediment module).

\begin{tabular}{lllll}
\hline & Atlantic & Pacific & Indian & Global \\
\hline Burial flux (Gt C yr & & & \\
TA* Inventory $\left(\mathrm{Pmol} \mathrm{C}^{-1}\right)$ & 0.011 & 0.062 & 0.042 & 0.117 \\
TA $^{*}$ obs & 2.5 & 27.9 & 7.0 & 37.4 \\
TA $^{*}$ sedcorr & 0.9 & 4.6 & 1.4 & 6.9 \\
TA $^{*}$ obs+sedcorr & 3.4 & 32.4 & 8.4 & 44.1 \\
TA $^{*}$ median & 5.4 & 31.1 & 8.7 & 45.5 \\
\hline
\end{tabular}

\subsubsection{A first-order correction for ocean-sediment TA* fluxes}

$\mathrm{CaCO}_{3}$ burial removes alkalinity from the ocean water column and lowers concentrations and the overall $\mathrm{TA}^{*}$ inventory relative to a run without the sediment module. Riverine input compensates this loss. This input of alkalinity is added to the surface ocean and by that to the part of the preformed alkalinity component $\left(\mathrm{TA}^{0}\right)$, leaving $\mathrm{TA}^{*}$ unchanged. $\mathrm{CaCO}_{3}$ export and dissolution within the water column and the corresponding fluxes of alkalinity and $\mathrm{TA}^{*}$ remain largely unchanged between runs with and without sediments.

Ideally, the ensemble would be run fully interactively with the sediment module enabled to account for all important processes within the $\mathrm{CaCO}_{3}$ cycle. However, this is computationally too expensive as the sediment module requires a long spin up to achieve equilibrium. A first-order correction term $\mathrm{TA}^{* \text { sedcorr }}$ that accounts for the influence of $\mathrm{CaCO}_{3}$ burial and dissolution fluxes on $\mathrm{TA}^{*}$ is estimated as follows. First, the skill scores are computed as described above with $\mathrm{TA}^{* \text { sedcorr }}$ set to zero. Then, the 14 best ensemble members are selected and rerun with the sediment module enabled. The mean difference in the $\mathrm{TA}^{*}$ fields between the simulations with and without sediments yields the sediment correction, $\mathrm{TA}^{* \text { sedcorr }}$.

These simulations with sediments yield a mean global burial flux of $0.12 \mathrm{Gt} \mathrm{Cyr}^{-1}$ (see Table 3: $0.011 \mathrm{Gt} \mathrm{C} \mathrm{yr}^{-1}$ in the Atlantic, $0.062 \mathrm{Gt} \mathrm{Cyr}^{-1}$ in the Pacific, and $0.042 \mathrm{Gt}$ $\mathrm{Cyr}^{-1}$ in the Indian Ocean). This is within the estimate by Feely et al. (2004) of 0.1-0.14 Gt Cyr ${ }^{-1}$.

The sediment burial correction on $\mathrm{TA}^{*}$ is largest in the Pacific and smallest in the Atlantic (Figs. 3 and 4). The global TA* inventory in runs with the sediment is $6.9 \mathrm{PmolC}$ lower compared to the runs without the sediment (see Table 3: $0.9 \mathrm{PmolC}$ in the Atlantic, 4.6 PmolC in the Pacific, and $1.4 \mathrm{PmolC}$ in the Indian Ocean). This reduction is equal to the inventory of the $\mathrm{TA}^{* \text { sedcorr }}$ correction and $\sim 16$ and $\sim 20 \%$ of the observation-derived $\mathrm{TA}^{*}$ inventory of the Pacific and Indian Ocean, respectively. $\mathrm{TA}^{*}$ concentrations are 


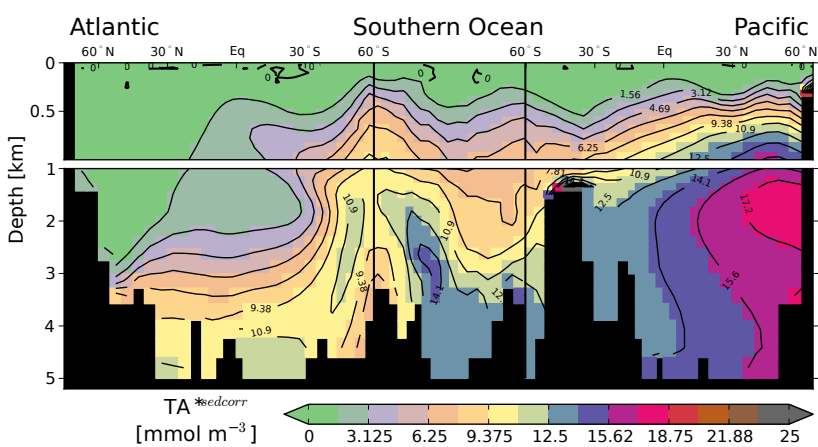

Figure 3. Influence of ocean-sediment fluxes on $\mathrm{TA}^{*}$. The mean offset in $\mathrm{TA}^{*}$ between simulations with and without the sediment module is shown for the 14 ensemble members with the highest skill. Displayed are results for a cross section through the Atlantic $\left(25^{\circ} \mathrm{W}\right)$, across the Southern Ocean $\left(58^{\circ} \mathrm{S}\right)$ into the Pacific, and through the Pacific $\left(175^{\circ} \mathrm{W}\right)$. Note the colour bar.
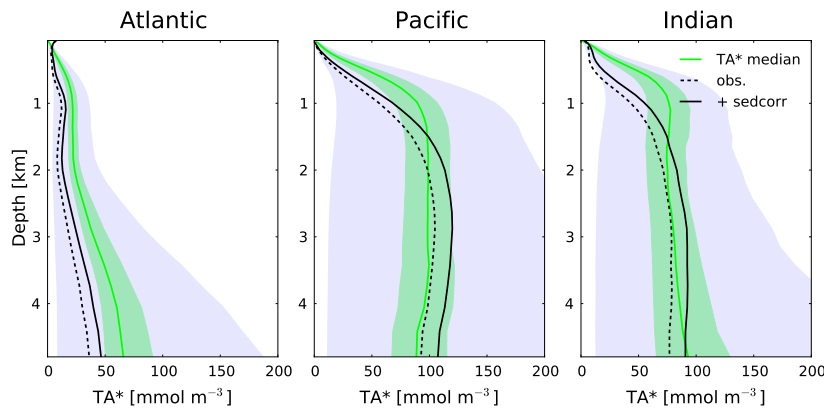

Figure 4. Model ensemble vs. observation-based basin-mean TA* profiles. The grey shading shows the unconstrained prior and the green shading shows the constrained ( $68 \%$ confidence interval) distribution of the model ensemble. Lines represent the median of the constrained ensemble (green), observation-based TA* (black dashes), and observation-based $\mathrm{TA}^{*}$ corrected for a sediment burial flux of $0.12 \mathrm{Gt} \mathrm{Cyr}^{-1}$ (black solid). The corresponding Southern Ocean sector is included in the averaging.

affected relatively uniformly below $1 \mathrm{~km}$ and differences in $\mathrm{TA}^{*}$ between simulations with and without the sediment module tend to vanish toward the surface ocean (Figs. 3 and 4). Correspondingly, the spatial patterns of TA* are very similar for simulations with and without sediments; correlation coefficients are $>0.99$. We expect that the correction will tend to increase the export flux of $\mathrm{CaCO}_{3}$ in the optimisation to compensate for the loss by burial, but will not strongly affect dissolution parameters as the spatial patterns of $\mathrm{TA}^{*}$ remain similar with or without correction.

A few caveats apply to this first-order estimate of $\mathrm{TA}^{* \text { sedcorr }}$. First, our approach involves a few, likely minor, technical inconsistencies. Aragonite is not treated explicitly in the sediment module and all $\mathrm{CaCO}_{3}$ is assumed to be in the form of calcite; this may tend to bias sediment burial high as calcite is less soluble. The saturation state within the sediments is computed interactively with modelled ocean boundary conditions; this may locally lead to inconsistencies, as $\mathrm{CaCO}_{3}$ dissolution within the ocean water column is computed using the prescribed, observation-based saturation state. The alkalinity flux associated with organic matter remineralisation within the sediment is not explicitly distinguished and included in the flux of $\mathrm{TA}^{*}$ from sediments to the ocean; this results in a bias on order of $5 \%$ in the redissolution flux and a negligible influence on the sediment correction.

\section{Results}

\subsection{Observation-derived vs. simulated $\mathrm{TA}^{*}$}

Reconstructed TA* (Fig. 1, TA*obs) is - by definition - close to zero at the ocean surface and correspondingly low within the well-ventilated North Atlantic Deep Water (NADW), Antarctic Intermediate and Mode Water, and within North Pacific Intermediate Water. TA* concentrations in the deep ocean are increasing with the age of water masses (see Fig. A2 of $\Delta^{14} \mathrm{C}$ which is a proxy for water mass age) as the dissolution of $\mathrm{CaCO}_{3}$ continues to add $\mathrm{TA}^{*}$ along the flow path. $\mathrm{TA}^{*}$ concentrations are around 40 to $50 \mathrm{mmol} \mathrm{m}^{-3}$ in the deep Atlantic (Antarctic bottom water, AABW) and in the deep Southern Ocean and increase to $130 \mathrm{mmolm}^{-3}$ in the northern Pacific. The reconstructed basin-mean profiles in the Pacific and Indian basin (Fig. 4) show strong gradients in the upper $1500 \mathrm{~m}$ and relatively uniform values below that. Concentrations are generally much lower in the Atlantic than in the Pacific.

The unconstrained model ensemble yields a large range of TA* concentrations (Fig. 4, grey shading). The optimisation procedure greatly reduces this range in simulated $\mathrm{TA}^{*}$ to a comparably narrow confidence interval (Fig. 4, green shading representing the $68 \%$ confidence interval). For example, basin-averaged concentrations in the deep Pacific $(4000 \mathrm{~m})$ range between 11 and $287 \mathrm{mmolm}^{-3}$ in the unconstrained ensemble, while the corresponding $68 \%$ confidence interval in $\mathrm{TA}^{*}$ is 73 to $122 \mathrm{mmolm}^{-3}$ in the constrained ensemble. The selected a priori parameter ranges are therefore wide enough to result in a very broad range of $\mathrm{TA}^{*}$ concentrations; the Bayesian optimisation framework confines this initial range around or close to the observation-based values.

The median field from the constrained model ensemble generally captures the observation-based TA* pattern (Fig. 5). The correlation coefficients $(r)$ between the two fields are $0.83,0.88$, and 0.87 in the Atlantic, Pacific, and Indian Ocean, respectively, and the RMSEs between the two fields are $17.7,23.8$, and $19.8 \mathrm{mmol} \mathrm{m}^{-3}$ for the respective basins. These deviations correspond, respectively, to 57, 28, and $28 \%$ of their mean $\mathrm{TA}^{*}$ concentration in each basin. Large positive deviations are found in the intermediate waters of the Pacific. This is also evident in the observationderived basin-mean profiles of $\mathrm{TA}^{*}$, which generally fall 

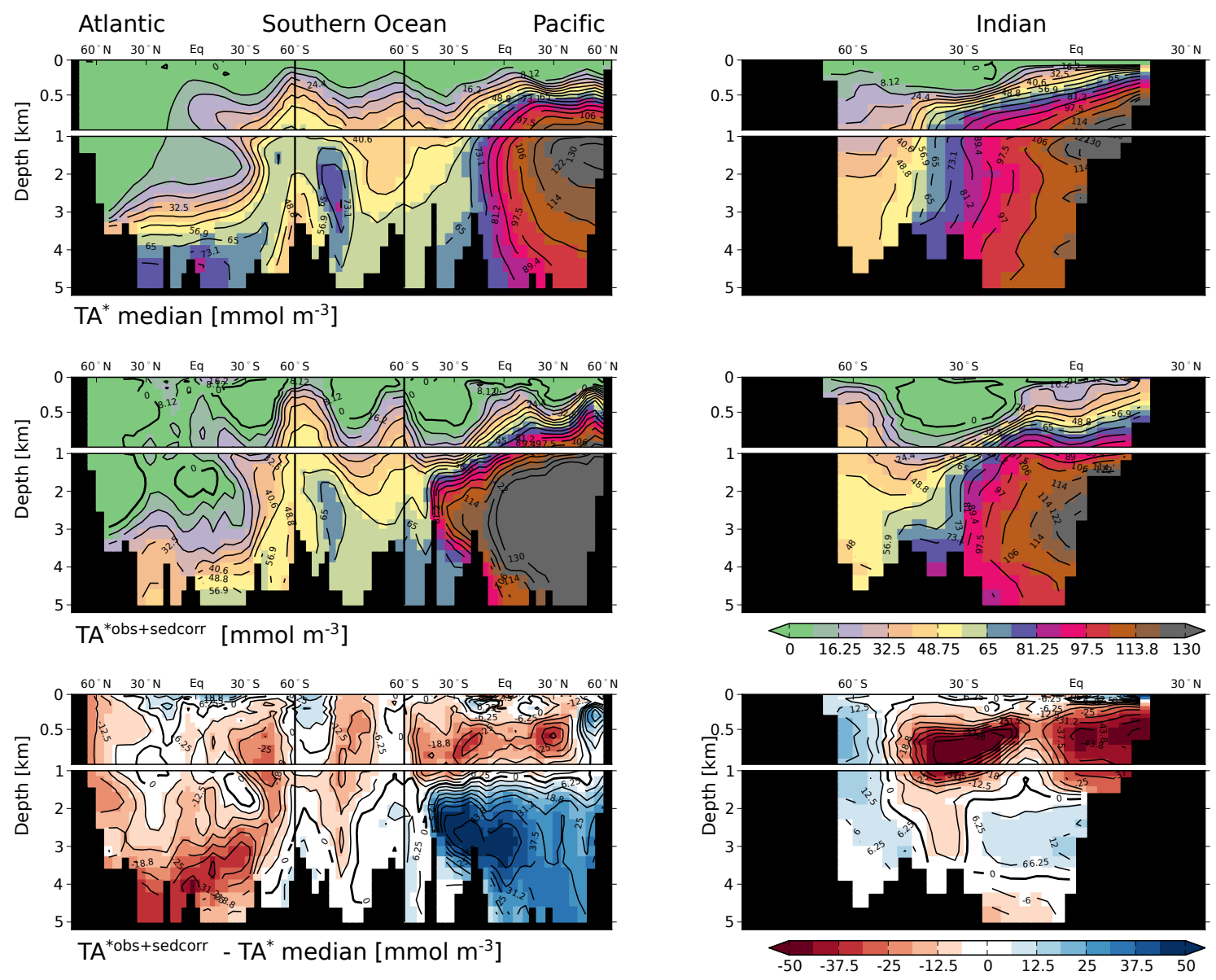

Figure 5. Observation-based vs. simulated TA*. Left column: modelled (median) $\mathrm{TA}^{*}$, observed $\mathrm{TA}^{*}$, and their difference in a cross section through the Atlantic $\left(25^{\circ} \mathrm{W}\right)$, Southern Ocean $\left(58^{\circ} \mathrm{S}\right)$, and Pacific $\left(175^{\circ} \mathrm{W}\right)$. Right column: the same for a cross section along $95^{\circ} \mathrm{E}$ in the Indian Ocean. The correlation coefficient, relative standard deviation $\left(\sigma_{\text {rel. }}^{\text {obs. }}\right)$, and root mean square error (RMSE) between the simulated and observation-based fields are $0.83,1.09$, and $17.7 \mathrm{mmol} \mathrm{m}^{-3}$ in the Atlantic; $0.88,0.8$, and $23.8 \mathrm{mmol} \mathrm{m}^{-3}$ in the Pacific; $0.87,0.86$, and $19.8 \mathrm{mmol} \mathrm{m}^{-3}$ in the Indian Ocean.

within the $68 \%$ confidence interval of the constrained model ensemble (Fig. 4). In the Atlantic, the ensemble median concentrations are, on basin-average, higher than the reconstructed ones. In the Pacific and Indian oceans, the median clearly overestimates $\mathrm{TA}^{*}$ in the thermocline (the $68 \%$ confidence range does not include the observations there) and somewhat underestimates $\mathrm{TA}^{*}$ in the deep ocean. This is likely linked to known deficiencies in the model's circulation. Intermediate and mode waters (with low $\mathrm{TA}^{*}$ concentrations) do not penetrate far enough towards the equator. As a consequence, mixing of $\mathrm{TA}^{*}$ depleted surface waters is too low and $\mathrm{TA}^{*}$ concentrations are too high in the thermocline. Alternatively, we cannot exclude that dissolution may be overestimated in the thermocline of the Pacific and Indian Ocean. This data-model mismatch could potentially be reduced by introducing more than one background dissolution rate constant $\left(k_{\mathrm{bg}}\right)$ or a depth-dependent particle sinking velocity. However, this may simply mask deficiencies in the circulation and we do not attempt such a solution. Generally, the correlation between observed and modelled $\mathrm{TA}^{*}$ is remarkably high.

\subsection{Probabilistic estimates of $\mathrm{CaCO}_{3}$ and alkalinity fluxes}

The estimated global median export flux of $\mathrm{CaCO}_{3}$ at $75 \mathrm{~m}$ - with its $68 \%$ confidence interval - is $0.90(0.72-1.05) \mathrm{Gt}$ $\mathrm{Cyr}^{-1}$ (Table 4 and Fig. 6). Basin-wide, we find $\mathrm{CaCO}_{3}$ median export fluxes (and $68 \%$ confidence intervals) of $0.12(0.078-0.17) \mathrm{Gt} \mathrm{Cyr}^{-1}$ from the Atlantic, 0.55 (0.39$0.68) \mathrm{Gt} \mathrm{Cyr}^{-1}$ from the Pacific, and $0.23(0.14-0.32) \mathrm{Gt}$ $\mathrm{Cyr}^{-1}$ from the Indian Ocean (Table 4 and Fig. 6). Regionally, largest export fluxes are simulated in the Southern Ocean sector of the Pacific, in the Pacific equatorial upwelling regions, and in the northwestern Pacific (Fig. 7). In the Indian Ocean, export fluxes are highest in its eastern tropical regions and in its section of the Southern Ocean. In the 
Table 4. Constrained fluxes (median and $68 \%$ confidence interval, c.i.) of biogenic $\mathrm{CaCO}_{3}\left(\mathrm{Gt} \mathrm{Cyr}^{-1}\right)$.

\begin{tabular}{|c|c|c|c|c|c|c|c|c|}
\hline & $\begin{array}{l}\text { Atlantic } \\
\text { median }\end{array}$ & c.i. & $\begin{array}{l}\text { Pacific } \\
\text { median }\end{array}$ & c.i. & $\begin{array}{l}\text { Indian } \\
\text { median }\end{array}$ & c.i. & $\begin{array}{l}\text { Global } \\
\text { median }\end{array}$ & c.i. \\
\hline \multicolumn{9}{|l|}{ Export at $75 \mathrm{~m}$} \\
\hline $70-30^{\circ} \mathrm{N}$ & 0.021 & {$[0.007-0.037]$} & 0.081 & {$[0.027-0.134]$} & & & & \\
\hline $30^{\circ} \mathrm{N}-35^{\circ} \mathrm{S}$ & 0.061 & {$[0.018-0.103]$} & 0.307 & [0.149-0.457] & 0.143 & [0.053-0.223] & & \\
\hline$>35^{\circ} \mathrm{S}$ & 0.041 & {$[0.014-0.07]$} & 0.174 & {$[0.057-0.254]$} & 0.088 & {$[0.03-0.14]$} & & \\
\hline $70^{\circ} \mathrm{N}-90^{\circ} \mathrm{S}$ & 0.121 & {$[0.078-0.171]$} & 0.549 & [0.391-0.697] & 0.23 & [0.137-0.316] & 0.897 & [0.72-1.049] \\
\hline \multicolumn{9}{|c|}{ Dissolution in waters shallower than $1500 \mathrm{~m}$} \\
\hline $70-30^{\circ} \mathrm{N}$ & 0.006 & {$[0.002-0.011]$} & 0.048 & {$[0.015-0.086]$} & & & & \\
\hline $30^{\circ} \mathrm{N}-35^{\circ} \mathrm{S}$ & 0.015 & {$[0.004-0.03]$} & 0.118 & {$[0.049-0.2]$} & 0.043 & [0.016-0.08] & & \\
\hline$>35^{\circ} \mathrm{S}$ & 0.01 & {$[0.003-0.021]$} & 0.043 & {$[0.013-0.082]$} & 0.02 & [0.006-0.042] & & \\
\hline $70^{\circ} \mathrm{N}-90^{\circ} \mathrm{S}$ & 0.033 & {$[0.018-0.054]$} & 0.216 & {$[0.125-0.32]$} & 0.064 & {$[0.032-0.11]$} & 0.328 & {$[0.202-0.444]$} \\
\hline \multicolumn{9}{|c|}{ Deposition on sediments shallower than $1500 \mathrm{~m}$} \\
\hline $70-0^{\circ} \mathrm{N}$ & 0.003 & {$[0.001-0.005]$} & 0.008 & {$[0.002-0.014]$} & & & & \\
\hline $30^{\circ} \mathrm{N}-35^{\circ} \mathrm{S}$ & 0.003 & {$[0.001-0.006]$} & 0.008 & {$[0.004-0.013]$} & 0.015 & {$[0.005-0.024]$} & & \\
\hline$>35^{\circ} \mathrm{S}$ & 0 & {$[0.0-0.001]$} & 0.007 & {$[0.002-0.011]$} & & {$[0.0-0.001]$} & & \\
\hline $70^{\circ} \mathrm{N}-90^{\circ} \mathrm{S}$ & 0.007 & {$[0.004-0.01]$} & 0.023 & {$[0.016-0.029]$} & 0.016 & {$[0.006-0.025]$} & 0.045 & {$[0.034-0.056]$} \\
\hline \multicolumn{9}{|c|}{ Dissolution in waters deeper or equal to $1500 \mathrm{~m}$} \\
\hline $70-30^{\circ} \mathrm{N}$ & 0.008 & [0.003-0.013] & 0.014 & [0.003-0.035] & & & & \\
\hline $30^{\circ} \mathrm{N}-35^{\circ} \mathrm{S}$ & 0.03 & {$[0.011-0.048]$} & 0.133 & {$[0.068-0.2]$} & 0.053 & {$[0.022-0.087]$} & & \\
\hline$>35^{\circ} \mathrm{S}$ & 0.023 & {$[0.009-0.038]$} & 0.085 & {$[0.031-0.129]$} & 0.043 & {$[0.015-0.07]$} & & \\
\hline $70^{\circ} \mathrm{N}-90^{\circ} \mathrm{S}$ & 0.06 & [0.039-0.083] & 0.233 & {$[0.165-0.305]$} & 0.097 & [0.061-0.139] & 0.395 & [0.32-0.469] \\
\hline \multicolumn{9}{|c|}{ Deposition on sediments deeper or equal to $1500 \mathrm{~m}$} \\
\hline $70-30^{\circ} \mathrm{N}$ & 0.003 & {$[0.0-0.007]$} & 0.002 & [0.001-0.007] & & & & \\
\hline $30^{\circ} \mathrm{N}-35^{\circ} \mathrm{S}$ & 0.009 & {$[0.001-0.021]$} & 0.031 & {$[0.012-0.062]$} & 0.019 & [0.005-0.039] & & \\
\hline$>35^{\circ} \mathrm{S}$ & 0.005 & {$[0.001-0.011]$} & 0.02 & {$[0.006-0.041]$} & 0.016 & {$[0.005-0.03]$} & & \\
\hline $70^{\circ} \mathrm{N}-90^{\circ} \mathrm{S}$ & 0.018 & {$[0.009-0.033]$} & 0.056 & [0.028-0.099] & 0.035 & {$[0.018-0.065]$} & 0.116 & {$[0.071-0.179]$} \\
\hline \multicolumn{9}{|c|}{ Deposition on all sediments } \\
\hline $70-30^{\circ} \mathrm{N}$ & 0.006 & {$[0.001-0.012]$} & 0.011 & {$[0.003-0.021]$} & & & & \\
\hline $30^{\circ} \mathrm{N}-35^{\circ} \mathrm{S}$ & 0.013 & {$[0.002-0.027]$} & 0.04 & {$[0.017-0.073]$} & 0.036 & {$[0.011-0.061]$} & & \\
\hline$>35^{\circ} \mathrm{S}$ & 0.005 & {$[0.001-0.012]$} & 0.028 & {$[0.008-0.051]$} & 0.016 & {$[0.005-0.03]$} & & \\
\hline $70^{\circ} \mathrm{N}-90^{\circ} \mathrm{S}$ & 0.025 & {$[0.014-0.043]$} & 0.081 & {$[0.049-0.126]$} & 0.052 & {$[0.026-0.087]$} & 0.164 & [0.113-0.227] \\
\hline
\end{tabular}

tropical and northern Atlantic, export fluxes are generally low, consistent with the low TA* values in the bulk of NADW and $\mathrm{AABW}$.

Median $\mathrm{CaCO}_{3}$ export production per unit area in the constrained ensemble is considerably lower in the Atlantic sector of the Southern Ocean (135 $\left.\mathrm{mmol} \mathrm{Cm}^{-2} \mathrm{yr}^{-1}\right)$ as compared to the Pacific ( $301 \mathrm{mmol} \mathrm{Cm}^{-2} \mathrm{yr}^{-1}$ ) and Indian $(326 \mathrm{mmol}$ $\mathrm{Cm}^{-2} \mathrm{yr}^{-1}$ ) sectors (Fig. 7 top). This is attributable to the choice of the regional boundaries for the rain-ratio regions, and the assumption that the spatial pattern of export within a region is identical to the pattern simulated by the standard version of the model. The standard model yields relatively little zonal variation in the $\mathrm{CaCO}_{3}$ export fluxes in the Southern Ocean in contrast to the data assimilation with lower than zonally averaged export in the Atlantic. This re- flects the much lower TA* reconstructed in the deep Atlantic as compared to the deep Pacific and Indian (Fig. 1). A large export in the Atlantic sector of the Southern Ocean tends to yield high simulated TA* concentrations in the Antarctic bottom water that fills the deep Atlantic. The Monte Carlo data assimilation therefore requires low $\mathrm{CaCO}_{3}$ export in the Atlantic sector to minimise model-data mismatches in the deep Atlantic. It is difficult to correctly represent water mass formation and circulation in the Southern Ocean and our model may be biased. A known bias is that the Atlantic bottom water circulation is too sluggish, also evidenced by simulated low radiocarbon signatures (Figs. A2 and A4). The influence of a potential bias in South Atlantic export on global $\mathrm{CaCO}_{3}$ export is estimated to be relatively small; assuming the same (median) $\mathrm{CaCO}_{3}$ export per unit area in the Atlantic 

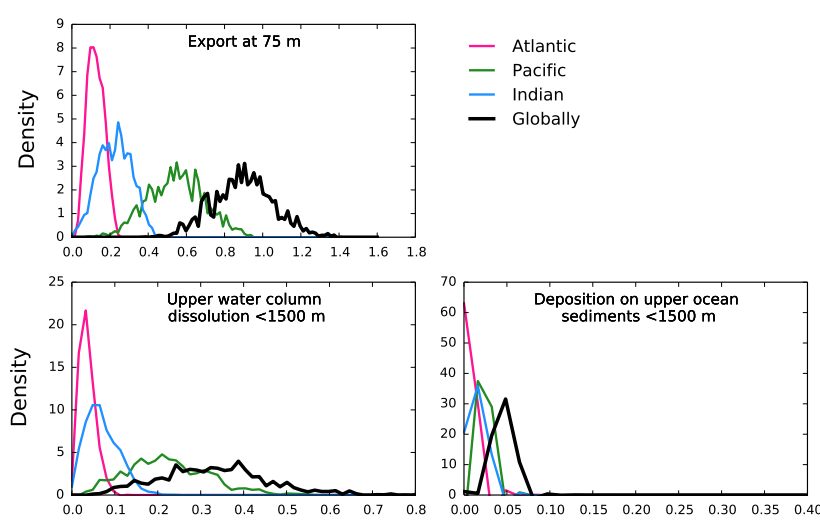

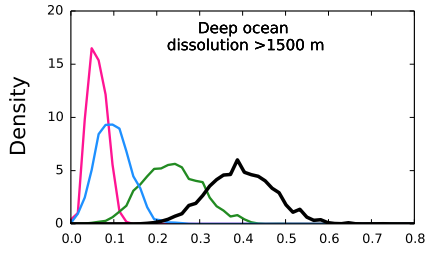

$\mathrm{CaCO}_{3}$ fluxes [Gt-C $\mathrm{yr}^{-1}$ ]

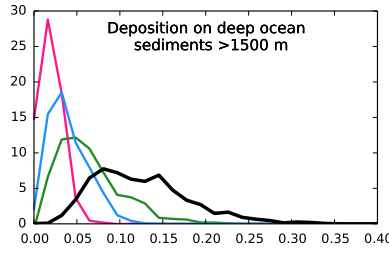

$\mathrm{CaCO}_{3}$ fluxes [Gt-C $\mathrm{yr}^{-1}$ ]
Figure 6. Probability density functions of basin-wide and global $\mathrm{CaCO}_{3}$ fluxes as constrained by the observation-based TA* distribution (corrected for a sediment burial flux of $0.12 \mathrm{Gt} \mathrm{C} \mathrm{yr}^{-1}$ ). Note the different scaling of the $x$ axes.

sector as estimated for the Indian sector would yield $0.06 \mathrm{Gt}$ $\mathrm{Cyr}^{-1}$ higher export than suggested by the ensemble median. While our Monte Carlo approach is suitable to estimate export fluxes over larger regions, the detailed spatial patterns in $\mathrm{CaCO}_{3}$ export remain unconstrained.

Globally, the deposition flux on the respective deepest cells integrates to $0.16(0.11-0.23) \mathrm{Gt}^{\mathrm{Cyr}^{-1}}$, i.e., $\sim 18 \%$ of the export flux (Fig. 7, Table 4). Local deposition depends on the local $\mathrm{CaCO}_{3}$ export and on how much dissolution is occurring in the water column, which itself depends on the saturation state and on the depth of the water column. Particularly in the North Atlantic, along coastlines, and in the Southern Ocean, high fluxes reach the ocean floor. These are dissolved into the water column in the ensemble set-up without the sediment module. Accordingly, $\sim 82 \%$ of the global median $\mathrm{CaCO}_{3}$ export dissolves in the water column. More specifically, $\sim 37 \%$ of the $\mathrm{CaCO}_{3}$ export dissolves in the upper water column above $1500 \mathrm{~m}, \sim 44 \%$ below $1500 \mathrm{~m}$ depth, with the remaining $\sim 18 \%$ dissolving at the sea floor (Table 4).

Average dissolution profiles for aragonite (red) and calcite (olive) in different ocean regions are displayed in Fig. 8. A peak in aragonite and calcite dissolution is located at or below the depth of the aragonite and calcite saturation horizon, respectively. These dissolution peaks are associated with the saturation-dependent dissolution rate coefficients (Eq. 5). As is the saturation horizon, these peaks are located deep down in the water column of the north and tropical Atlantic region (at 3-4 km depth for aragonite), at intermediate depth
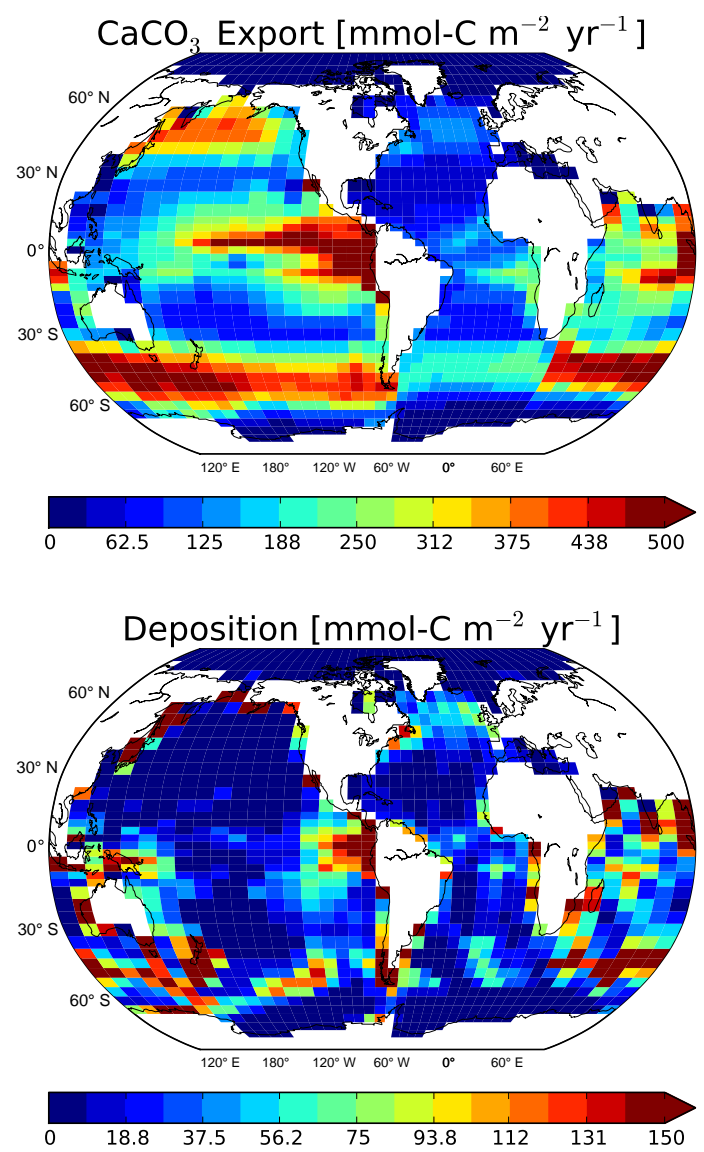

Figure 7. Top: median $\mathrm{CaCO}_{3}$ export, globally 0.90 (0.72-1.05) $\mathrm{Gt} \mathrm{Cyr}^{-1}$. Bottom: median $\mathrm{CaCO}_{3}$ fluxes reaching the ocean floor, globally $0.164(0.113-0.227) \mathrm{Gt} \mathrm{Cyr}^{-1}$. Note the different scaling of the colour bars.

of the South Atlantic, Indian, and Pacific (1.5 km for aragonite) and at relatively shallow depth of the tropical and north Pacific region $(\sim 700 \mathrm{~m}$ for aragonite). As the calcite saturation horizon is found deeper in the water column than the aragonite saturation horizon, so are these dissolution peaks located deeper down in the water column for calcite than for aragonite.

Our constrained ensemble includes non-zero values for the background dissolution rate. Consequently, calcite and aragonite dissolve throughout the water column, irrespective of the saturation state in the Atlantic, Pacific, and Indian Ocean. The percentage of the export flux, which dissolves in waters supersaturated with respect to calcite are $72(60-80), 43$ (30$53)$, and $68 \%(55-78 \%)$ in the Atlantic, Pacific, and Indian Ocean, respectively. We will further investigate in Sect. 4.4 to which extent the finding that a fraction of the $\mathrm{CaCO}_{3} \mathrm{ex}-$ port dissolves above the calcite saturation horizon and our export and dissolution flux estimates are robust. 

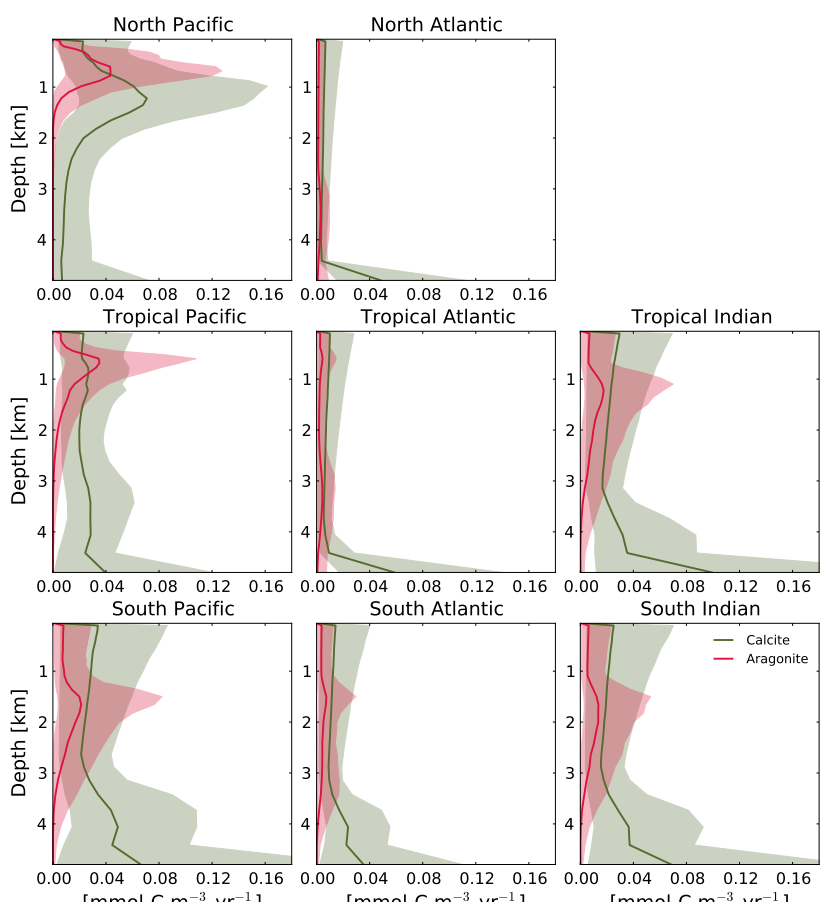

Figure 8. Constrained open water dissolution rate profiles for aragonite (red) and calcite (olive). Ensemble medians (solid lines) and $68 \%$ confidence intervals (shadings) are for spatial averages across individual regions and only include grid cells where the model water column extends to a depth of $5000 \mathrm{~m}$.

\subsection{Sensitivity of results to ocean-sediment interactions, and circulation}

\subsubsection{Ocean-sediment interactions}

As discussed in Sect. 3.3, $\mathrm{CaCO}_{3}$ deposition on, burial within, and redissolution from ocean sediments affects $\mathrm{TA}^{*}$ concentrations mainly in the Pacific and Indian Ocean in our model. To assess uncertainties in $\mathrm{CaCO}_{3}$ fluxes arising from uncertainties associated with the sediment correction, we set the sediment correction ( $\mathrm{TA}^{* \text { sedcorr }}$ ) of the $\mathrm{TA}^{*}$ field to zero to calculate potential skill scores (Eq. 9). This alternative case also illustrates the potential error due to the neglect of oceansediment fluxes. Export fluxes of $\mathrm{CaCO}_{3}$ are 2, 12, 8, and $8 \%$ smaller in the Atlantic, Pacific, Indian, and global ocean, respectively, while the variance is about the same. This is not surprising as we have already noted (Sect. 3.3) that a certain burial flux tends to decrease the $\mathrm{TA}^{*}$ pattern uniformly, i.e. the simulations with and without the sediment correlate highly in terms of TA*. The PDF of fluxes is therefore shifted to higher export fluxes, while the preference for dissolution parameters remains the same. The $\mathrm{CaCO}_{3}$ that dissolves above $1500 \mathrm{~m}$ is $4 \%$ higher, $5 \%$ lower, the same, and $4 \%$ lower in the Atlantic, Pacific, Indian, and global ocean, respectively, if sediment fluxes are neglected.

\subsubsection{Implications of different diapycnal diffusivities illustrated for three dissolution rate profiles}

The diapycnal diffusivity, $k_{\mathrm{dia}}$ of the model is varied to probe uncertainties related to the magnitude of the ocean overturning circulation. $k_{\mathrm{dia}}$ is either set to 0.1 (low), 0.2 (standard), or 0.5 (high) $\times 10^{-4} \mathrm{~m}^{2} \mathrm{~s}^{-1}$. Increasing $k_{\mathrm{dia}}$ increases the strength of the overturning circulation, and deep ocean ventilation. Maximum Atlantic Meridional Overturning is 16, 18, and $23 \mathrm{~Sv}$ (Sverdrups), Southern Ocean overturning is -16 , -14 , and $-15 \mathrm{~Sv}$, and maximal deep Pacific overturning is $-13,-14$, and $-20 \mathrm{~Sv}$ for the low, standard, and high $k_{\text {dia }}$ simulations, respectively. We compare the simulated (natural) ${ }^{14} \mathrm{C}$ of DIC and CFC11 distributions to their corresponding observations (Key et al., 2004) to evaluate the physical transport (see Appendix). Both are conservative tracers and are indicative of the ventilation timescales of the deep ocean and the thermocline, respectively. The observationbased (Key et al., 2004) global mean (natural) $\Delta^{14} \mathrm{C}$ of DIC is $-151 \%$. The reference simulation achieves a mean (natural) $\Delta^{14} \mathrm{C}$ of DIC of $-160 \%$. Correspondingly, ocean radiocarbon signatures become too low $(-176 \%$ ) with the low diapycnal mixing rate and too high with the high $(-126 \%$ o) diapycnal mixing rate (see Fig. A4). Simulated surface-todeep $\Delta^{14} \mathrm{C}$ gradients are too low (high) relative to the observed gradients for the high (low) diapycnal diffusivity parameter, thereby indicating surface-to-deep water exchange that is too fast (slow) (Fig. A4). The global observation-based CFC11 inventory is estimated to $575 \mathrm{Mmol}$. The reference simulation yields $513 \mathrm{Mmol} \mathrm{CFC} 11$ as the mean inventory over the modelled period between 1990 and 2000. In the low mixing simulation, this inventory is even lower $(479 \mathrm{Mmol})$ and in the high mixing simulation it is too high $(631 \mathrm{Mmol})$. On a global scale, our reference choice is therefore in better agreement with these physical tracers (see Fig. A4).

We vary $k_{\text {dia }}$ for three illustrative dissolution rate profiles introduced in Sect. 3.2 (see Fig. 2 and Table 2). In the low diapycnal diffusivity case, $\mathrm{CaCO}_{3}$ export is $11 \%$ lower and in the high diapycnal diffusivity case, $\mathrm{CaCO}_{3}$ export is $30 \%$ higher compared to the standard case. Larger overturning and mixing yields more nutrient input into the euphotic zone and thus more organic matter export. $\mathrm{CaCO}_{3}$ export is independent of alkalinity in our model and does not depend on the choice of the dissolution rate. The simulated $\mathrm{TA}^{*}$ patterns remain similar, and correlation between the patterns is at least 0.93 . Basin-average profiles in $\mathrm{TA}^{*}$ vary little in the upper ocean and the deep Pacific $\left(<14 \mathrm{mmol} \mathrm{m}^{-3}\right)$ and modestly in the deep Atlantic $\left(<44 \mathrm{mmol} \mathrm{m}^{-3}\right)$ and deep Indian $\left(<18 \mathrm{mmol} \mathrm{m}^{-3}\right)$ when varying diapycnal diffusivity between 0.1 and $0.5 \times 10^{-4} \mathrm{~m}^{2} \mathrm{~s}^{-1}$. Perhaps somewhat surprisingly, the simulated $\mathrm{TA}^{*}$ inventory is relatively weakly affected by the choice of $k_{\text {dia }}$; the global $\mathrm{TA}^{*}$ inventory varies by less than $7 \%$ across the range of $k_{\text {dia }}$ (Table 2). In other words, variations in the magnitude of ocean ventilation hardly affect the $\mathrm{TA}^{*}$ inventory for a given dissolution rate 

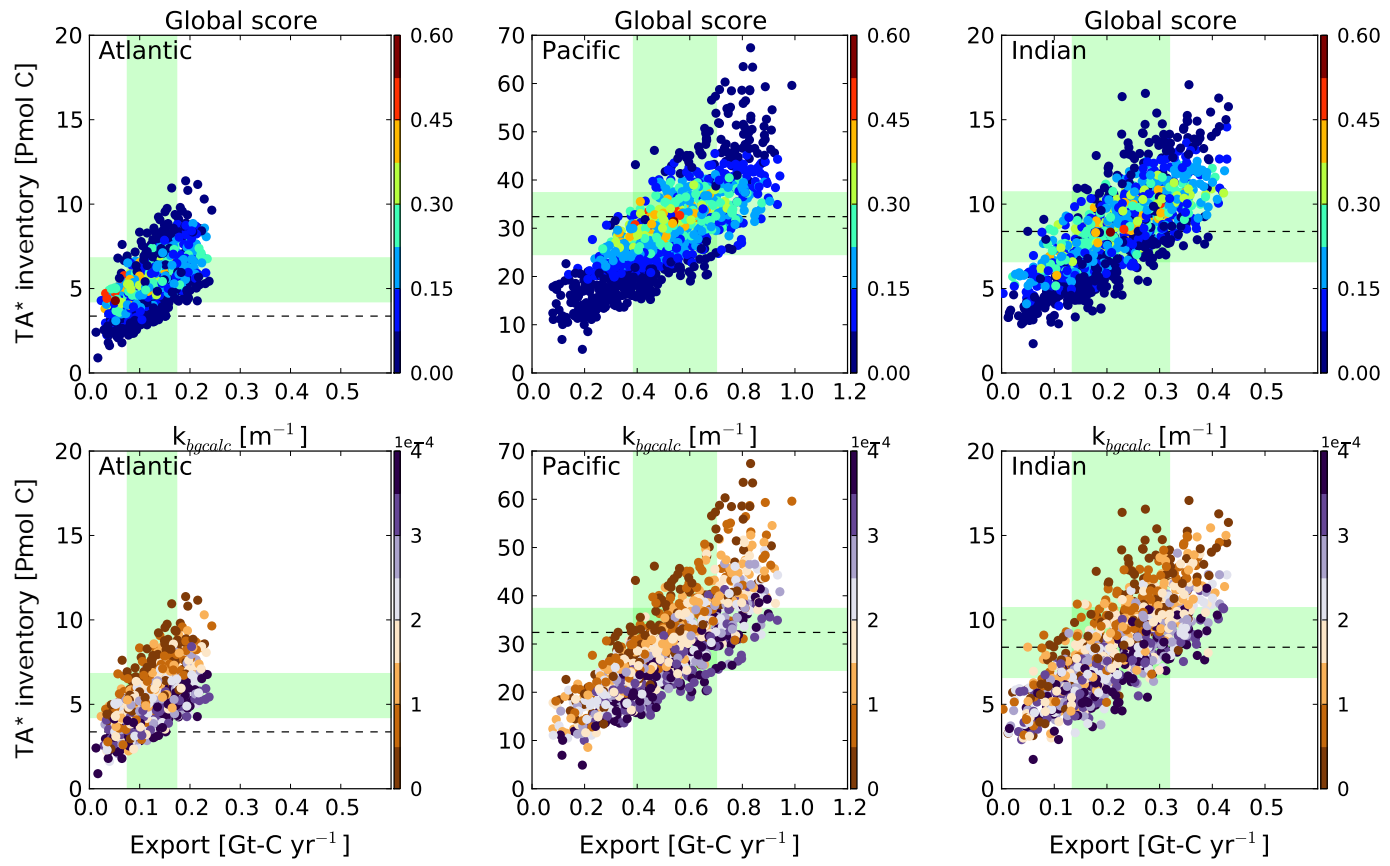

Figure 9. The simulated $\mathrm{TA}^{*}$ inventory vs. the simulated $\mathrm{CaCO}_{3}$ export of each ensemble member, coloured according to model skill (top) and background dissolution rate (bottom) for the Atlantic, Pacific, and Indian Ocean (columns). Each circle represents results from an individual simulation. Green shadings show the $68 \%$ confidence range in basin-wide $\mathrm{TA}^{*}$ inventories and $\mathrm{CaCO}_{3}$ export of the constrained model ensemble, and black dashed lines indicate the estimated TA* inventories based on the observations including the sediment correction. Runs with low and high background dissolution can skillfully represent the $\mathrm{TA}^{*}$ distribution. Runs with a higher $\mathrm{CaCO}_{3}$ export tend to require a higher background dissolution to achieve a good skill.

profile. Higher (lower) export under higher (lower) mixing compensate each other. These changes in $\mathrm{TA}^{*}$ inventory are smaller than the influence of the sediment correction (see Table 3) or the choice of the dissolution profile. In conclusion, simulated $\mathrm{TA}^{*}$ is only weakly affected by uncertainties in the diapycnal mixing coefficient.

The choice of the dissolution rate profile has a substantial influence on the simulated TA* inventory (Table 2). As mentioned previously, $\mathrm{TA}^{*}$ accumulates in the deep ocean when all $\mathrm{CaCO}_{3}$ is dissolved below the saturation horizon of aragonite and calcite and no dissolution is permitted above. This raises the question whether surface-to-deep transport is too slow in our model. As mentioned above, the radiocarbon signatures as well as $\mathrm{CFC} 11$ concentrations are on average close to observations (Figs. A3 and A2). Increasing ocean ventilation by increasing $k_{\text {dia }}$ results in radiocarbon signatures that are too young and CFC11 concentrations that are higher than observed. However, it does not substantially reduce the overestimation of the $\mathrm{TA}^{*}$ inventory in those cases.

\subsection{How to parameterise $\mathrm{CaCO}_{3}$ dissolution in an Earth system model}

An important question is how to formulate the dissolution rate of calcite and aragonite particles in Earth system models. Should the dissolution rate be a function of the simu- lated aragonite and calcite saturation state of the surrounding water? Should dissolution above the saturation horizon be permitted? We analyse the relationship between model skill, dissolution parameterisation, $\mathrm{CaCO}_{3}$ export, and $\mathrm{TA}^{*}$ inventories in the model ensemble (see Fig. 9) to address these questions. To achieve a high skill (green-to-red coloured dots in the upper panels of Fig. 9), an individual ensemble member needs to reproduce the observation-based TA* inventory (dashed line) within a limited range. We identify an export range within which $\mathrm{TA}^{*}$ can be reproduced skillfully (vertical green range in the upper panels of Fig. 9). Surprisingly, a high skill is achieved across the range of different dissolution schemes applied and for a broad range of parameter values. In other words, neither the dissolution scheme nor its parameters are well constrained by the observationbased TA* field. This is illustrated by plotting the value of the background dissolution rate, $k_{\mathrm{bg}}$ (lower panels of Fig. 9), as a function of the TA* inventory and export. Generally, the higher the global $\mathrm{CaCO}_{3}$ export flux, the higher the background dissolution rate required to achieve a high skill. Likewise, lower export can be distributed skillfully without dissolution in supersaturated waters $\left(k_{\mathrm{bg}}=0\right)$. Apparently, there are trade-offs between the magnitude of export and the applied dissolution parameterisation in terms of TA*, suggesting that export and dissolution parameters can only be con- 
strained simultaneously within limits when using $\mathrm{TA}^{*}$ as the only constraint.

These findings are in line with the results from our sensitivity simulations (Fig. 2, Table 2). The parameterisation with dissolution above the saturation horizon (constant) yields the lowest TA* inventory, followed by the scheme with fast dissolution below the saturation horizon, and the scheme with dissolution near the ocean floor (slow). A high (low) export is thus required for parameterisations with high (low) dissolution above the saturation horizon to simulate the observationbased TA* . Further, the different dissolution schemes yield highly correlated $\mathrm{TA}^{*}$ fields; the correlation coefficient between the global fields from the fast and slow dissolution scheme is 0.84 , and between the fields from the fast and constant scheme is 0.88 in simulations with the same $\mathrm{CaCO}_{3}$ export (Fig. 2). The average RMSE between the fast and slow dissolution scheme is $43.2 \mathrm{mmol} \mathrm{m}^{-3}$ and between the fast and constant is $24.5 \mathrm{mmol} \mathrm{m}^{-3}$. The high spatial correlation in simulated $\mathrm{TA}^{*}$ and uncertainties in $\mathrm{CaCO}_{3}$ export make it difficult to distinguish different dissolution parameterisations. The magnitude of $\mathrm{CaCO}_{3}$ exports modulates absolute TA* concentrations and thus model-data bias and root mean square errors. Given these uncertainties, we cannot objectively determine the preferred dissolution scheme.

\subsection{Flux measurements as additional constraint}

Global sediment trap data represent another observational constraint of the $\mathrm{CaCO}_{3}$ cycle. The database of Wilson et al. (2012, see Fig. A5) includes 156 measurements globally and is an update of the Honjo et al. (2008) compilation. For comparison, we constrained the model ensemble using these sediment trap data instead of the $\mathrm{TA}^{*}$ data as target (Figs. A5 and A6). Skill scores are calculated individually for the $\mathrm{Pa}$ cific, Atlantic, and Indian Ocean. $\mathrm{CaCO}_{3}$ export fluxes, dissolution profiles, and parameters constrained with the sediment trap data are consistent within uncertainties with those constrained by the $\mathrm{TA}^{*}$ data. The sediment trap data, however, yield wider uncertainty ranges, as illustrated in Fig. A6, and therefore do not permit us to reduce uncertainty ranges any further.

\section{Discussion}

\subsection{Export of $\mathrm{CaCO}_{3}$}

Berelson et al. (2007) summarised current estimates of $\mathrm{CaCO}_{3}$ export out of the euphotic zone (based on models and data) to $0.4-1.8 \mathrm{Gt} \mathrm{Cyr}^{-1}$ (spanning factor $\sim 4$ ). Our constrained median estimate of $\sim 0.90$ (ensemble range: $0.72-$ 1.05) $\mathrm{Gt} \mathrm{Cyr}^{-1}$ therefore lies at the lower end of these previously published estimates. In the end, these authors suggest that global $\mathrm{CaCO}_{3}$ export must be higher than $1.6 \mathrm{Gt} \mathrm{Cyr}^{-1}$. This estimate is based on sediment trap data and other information constraining the flux to the deep ocean $(>2000 \mathrm{~m})$

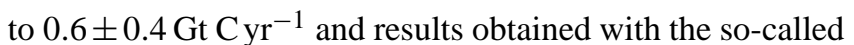
TA* CFC age method, suggesting an upper ocean dissolution of $1 \mathrm{Gt} \mathrm{Cyr}^{-1}$. The TA* CFC age method is heavily criticised by Friis et al. (2006) and tends to bias estimates systematically towards high values (Friis et al., 2006). This method and its shortcomings are further discussed in the next section on upper ocean dissolution. While our estimated flux to the deep ocean of $0.52(0.43-0.61) \mathrm{Gt} \mathrm{Cyr}^{-1}$ is roughly consistent with the budget of Berelson et al. (2007), their export estimate, and upper ocean dissolution, is in clear conflict with our results and those of other studies (Lee, 2001; Sarmiento and Gruber, 2006; Jin et al., 2006) that apply a range of different methodologies. We attribute this mismatch to deficiencies in the TA* CFC age method, implying that the export estimate by Berelson et al. (2007) is biased high.

Global-scale $\mathrm{CaCO}_{3}$ export has been previously estimated (see Fig. 10). Jin et al. (2006) diagnosed a global $\mathrm{CaCO}_{3}$

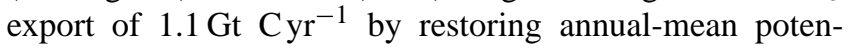
tial alkalinity to observations (Key et al., 2004) in the euphotic zone and in the whole water column within the Modular Ocean Model. Sediment burial and sediment-ocean fluxes are included implicitly in this approach. They provide a relatively small uncertainty range of 0.8 to $1.2 \mathrm{Gt} \mathrm{Cyr}^{-1}$ which falls within our range. Most of the uncertainty is attributed to uncertainties in the alkalinity data by these authors. Sarmiento and Gruber (2006) estimated $\mathrm{CaCO}_{3}$ export $\left(\sim 0.5 \mathrm{Gt} \mathrm{Cyr}^{-1}\right.$ ) by combining satellite NPP (as a mean of the three algorithms; Behrenfeld and Falkowski, 1997; Carr, 2002; Marra et al., 2003) with the organic particle export model of Dunne et al. (2005) and the rain-ratio estimate of Sarmiento et al. (2002). Lee (2001) derived net $\mathrm{CaCO}_{3}$ production $\left(\sim 0.92 \pm 0.3 \mathrm{Gt} \mathrm{Cyr}^{-1}\right)$ from seasonal potential alkalinity decreases. Both approaches focus on information of the surface ocean without taking advantage of information displayed in the full biogeochemical depth profile. In addition, Ridgwell et al. (2007) used an ensemble Kalman filter approach to assimilate total alkalinity and phosphate data into their model and determined a global $\mathrm{CaCO}_{3}$ export flux of $1.2 \mathrm{Gt} \mathrm{Cyr}^{-1}$. On average, these four studies yield a global mean $\mathrm{CaCO}_{3}$ export of $0.93 \mathrm{Gt} \mathrm{Cyr}^{-1}$, close to our median estimate of $0.90 \mathrm{Gt} \mathrm{Cyr}^{-1}$.

We find peaks in zonally averaged export in the North Pacific, the tropical Pacific and Indian, and in the Southern Ocean and low export fluxes in the subtropics and the tropical Atlantic (Fig. 11). This is in agreement with the results of Jin et al. (2006) and Lee (2001), with the exception that Lee (2001) suggested little $\mathrm{CaCO}_{3}$ export in all tropical regions. A significant $\mathrm{CaCO}_{3}$ export in the tropics is consistent with deep ocean sediment trap data (Francois et al., 2002; Berelson et al., 2007). As noted by Jin et al. (2006), the low estimates of Lee (2001) for tropical regions are likely related to small signals in seasonal alkalinity in the tropics, hampering their calculations. Concerning the magnitude of the export, our zonally averaged values are similar to these two studies in the Pacific sector of the Southern Ocean, and smaller in 

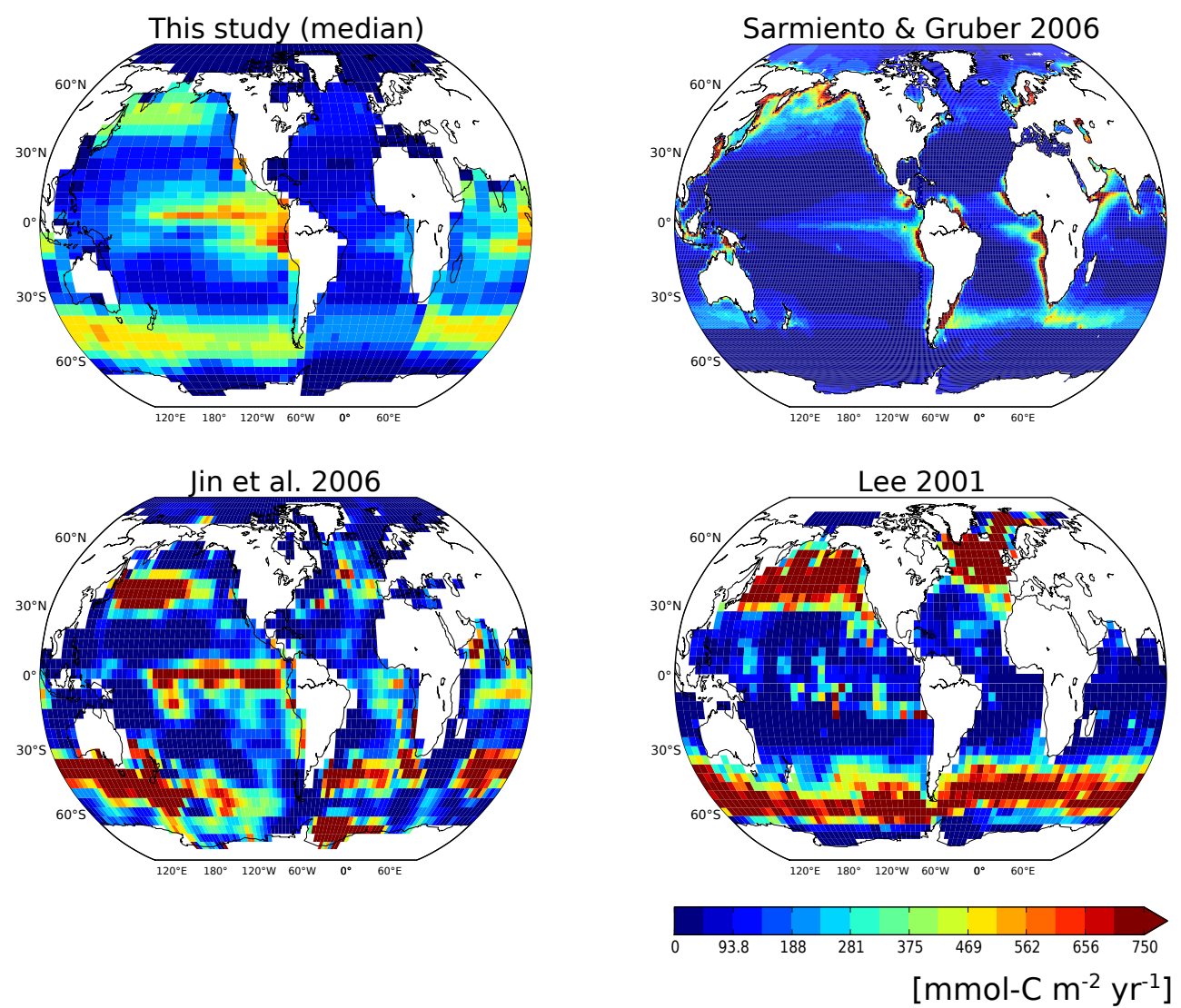

Figure 10. Observationally constrained $\mathrm{CaCO}_{3}$ export fields as estimated by different studies. Global total export is estimated to be 0.5 by Sarmiento and Gruber (2006), 1.14 by Jin et al. (2006), 1.1 by Lee (2001), and $0.90 \mathrm{Gt} \mathrm{Cyr}^{-1}$ by this study.

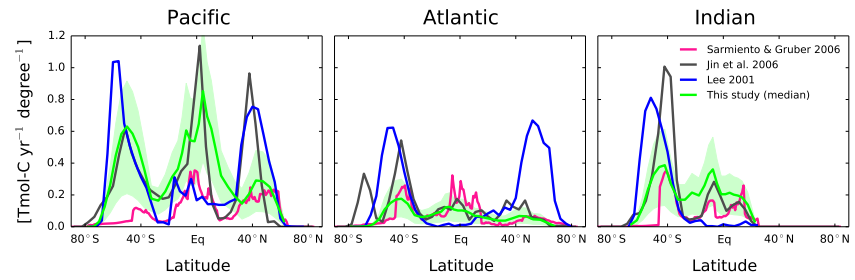

Figure 11. Zonally integrated export fluxes of the constrained Bern3D model ensemble (median and $68 \%$ confidence interval) compared to estimates by Sarmiento and Gruber (2006), Jin et al. (2006), and Lee (2001).

the Atlantic and Indian Southern Ocean sectors as well as in the North Pacific.

Interestingly, Lee (2001) found significant $\mathrm{CaCO}_{3}$ export in the North Atlantic, in contrast to Jin et al. (2006), Sarmiento and Gruber (2006), and this study. The relatively low North Atlantic export suggested by these latter studies appears to be in conflict with the occurrence of coccolithophorid blooms in this region (Brown and Yoder, 1994). On the other hand, the low TA* inventory in the Atlantic (Fig. 1) argues for a limited export of $\mathrm{CaCO}_{3}$ in this basin.
Carter et al. (2014) defined another alkalinity tracer, termed Alk*, that isolates the portion of the alkalinity signal that varies in response to calcium carbonate cycling and exchanges with terrestrial and sedimentary environments from the portion that varies in response to freshwater and organic matter cycling. These authors compiled a riverine input of alkalinity into the low-latitude Atlantic $\left(>40^{\circ} \mathrm{S}\right.$ and $\left.<40^{\circ} \mathrm{N}\right)$ equivalent to $0.057 \mathrm{Gt} \mathrm{Cyr}^{-1}$, which is $\sim 40 \%$ of the global continentally derived alkalinity. Their Alk* tracer in the Atlantic has the lowest open-ocean surface concentrations despite this large riverine source. They conclude that these large riverine inputs must therefore be more than balanced by strong net $\mathrm{CaCO}_{3}$ formation. For comparison, our estimates of $\mathrm{CaCO}_{3}$ export between $35^{\circ} \mathrm{S}$ and $30^{\circ} \mathrm{N}$ in the Atlantic are $0.06(0.018-0.1) \mathrm{Gt} \mathrm{Cyr}^{-1}$. We note, however, that a direct comparison between these two studies remains difficult. The river input does not strictly have to be compensated by the export flux but rather by the burial flux. In addition, the river input gets mixed and is subducted and transported southward by North Atlantic Deep Water, and the interpretation of concentrations without explicit consideration of transport and mixing is always difficult. 
Table 5. Dissolution rates of biogenic $\mathrm{CaCO}_{3}\left[\mathrm{Gt} \mathrm{Cyr}^{-1}\right]$ in the upper water column (200-1500 $\mathrm{m}$ depth levels) based on the TA* CFC age method as summarised in Berelson et al. (2007), and as constrained by $\mathrm{TA}^{*}$ data in our Latin hypercube ensemble (including the sediment correction, median and $68 \%$ c.i.). The dissolution estimates by Berelson et al. (2007) were assigned an estimated uncertainty of $\sim 50 \%$.

\begin{tabular}{lrrr}
\hline Location & $\begin{array}{r}\text { Berelson et al. } \\
(2007)\end{array}$ & $\begin{array}{r}\text { This study } \\
\text { median }\end{array}$ & c.i. \\
\hline Atlantic & & & \\
\hline$>40^{\circ} \mathrm{N}$ & 0.060 & 0.006 & {$[0.002-0.011]$} \\
$40^{\circ} \mathrm{N}-40^{\circ} \mathrm{S}$ & 0.010 & 0.02 & {$[0.008-0.036]$} \\
$>40^{\circ} \mathrm{S}$ & 0.040 & 0.009 & {$[0.003-0.017]$} \\
\hline Pacific & & & \\
\hline$>40^{\circ} \mathrm{N}$ & 0.070 & 0.039 & {$[0.013-0.067]$} \\
$40^{\circ} \mathrm{N}-5^{\circ} \mathrm{N}$ & 0.330 & 0.063 & {$[0.032-0.099]$} \\
$5^{\circ} \mathrm{N}-5^{\circ} \mathrm{S}$ & 0.020 & 0.035 & {$[0.015-0.058]$} \\
$5^{\circ} \mathrm{S}-40^{\circ} \mathrm{S}$ & 0.000 & 0.039 & {$[0.019-0.066]$} \\
$>40^{\circ} \mathrm{S}$ & 0.160 & 0.034 & {$[0.011-0.061]$} \\
\hline Indian & & & \\
\hline $40^{\circ} \mathrm{N}-40^{\circ} \mathrm{S}$ & 0.160 & 0.062 & {$[0.026-0.104]$} \\
$>40^{\circ} \mathrm{S}$ & 0.140 & 0.021 & {$[0.009-0.038]$} \\
\hline Total & 1.0 & 0.346 & {$[0.225-0.461]$} \\
\hline
\end{tabular}

Regional patterns of $\mathrm{CaCO}_{3}$ export (Fig. 10) vary among the different studies. In our approach $\mathrm{CaCO}_{3}$ export fluxes are scaled by a rain ratio to simulated export of particulate organic carbon within each of the eight considered regions. Thus, the total export for the three Southern Ocean sectors, the Indian Ocean, the tropical and northern Pacific, and the tropical and northern Atlantic is constrained by the TA* data, but not the pattern within each of these regions.

\section{2 $\mathrm{CaCO}_{3}$ dissolution in the upper ocean}

The $\mathrm{CaCO}_{3}$ leaving the surface ocean dissolves within the water column, at the sea floor, or gets buried. Berelson et al. (2007) get to global dissolution rates of $\sim 1 \mathrm{Gt} \mathrm{Cyr}^{-1}$ within upper level waters, clearly higher than our $\mathrm{TA}^{*}$-based estimate of $0.35(0.26-0.46) \mathrm{Gt} \mathrm{Cyr}^{-1}$. On a regional level, only two out of ten regional estimates by Berelson et al. (2007) are within our uncertainty ranges; these are the estimates for the tropical Pacific (taken as $5^{\circ} \mathrm{N}$ to $5^{\circ} \mathrm{S}$ ) and the low- and mid-latitude Atlantic $\left(40^{\circ} \mathrm{S}\right.$ to $\left.40^{\circ} \mathrm{N}\right)$ (Table 5). High dissolution rates in the range of $\sim 0.1$ to $0.4 \mathrm{mmol}$ $\mathrm{C} \mathrm{m}^{-3} \mathrm{yr}^{-1}$ are estimated by Barrett et al. (2014) for a transect in the upper tropical and northern North Atlantic. These values are much larger than our estimates of order $0.01 \mathrm{mmol}$ $\mathrm{Cm}^{-3} \mathrm{yr}^{-1}$ for the upper tropical and northern Atlantic. These high estimates are based on the measured decrease of suspended $\mathrm{CaCO}_{3}$ particles with depth multiplied by a
$\mathrm{CaCO}_{3}$ particle settling velocity of $80 \mathrm{~m} \mathrm{day}^{-1}$ and neglecting any temporal trend in the $\mathrm{CaCO}_{3}$ particle concentration. These estimates may be affected by uncertainties in the assumed particle settling velocity. $\mathrm{CaCO}_{3}$ particles settling velocities are reported by Jansen et al. (2002), to vary greatly ( 0.15 to $3440 \mathrm{~m} \mathrm{day}^{-1}$ ) and to be typically of the order of $1 \mathrm{mday}^{-1}$ for coccolitophorides and several $100 \mathrm{mday}^{-1}$ for foraminifera and pteropods. Our dissolution rates would be consistent with the measured depth gradient in suspended biogenic $\mathrm{CaCO}_{3}$ particles for an average settling velocity of a few day $^{-1}$.

As mentioned above, we link the differences between the estimates of Berelson et al. (2007) and this study to methodological problems (Friis et al., 2006) associated with the TA* CFC age method that very likely introduce a high bias in the results of Berelson et al. (2007). The TA* CFC age method relies on deduced, observation-derived $\mathrm{TA}^{*}$ concentrations and estimates of water mass age, typically derived from measurements of chlorofluorocarbons (CFCs) and their known atmospheric history. $\mathrm{TA}^{*}$ concentrations are plotted against their CFC age and a line is fitted to this data. The higher the $\mathrm{TA}^{*}$ concentration for a given water mass, the more $\mathrm{TA}^{*}$ must have been added by dissolution to this particular water parcel according to this method. The slope of the relationship between $\mathrm{TA}^{*}$ and age is in this sense the $\mathrm{CaCO}_{3}$ dissolution rate (mol volume ${ }^{-1}$ time $^{-1}$ ).

The method has been criticised for its neglect of explicit transport and mixing processes. In particular, Friis et al. (2006) noted that TA* signals ended up above the saturation horizon in their model run, even though there was explicitly no dissolution allowed to occur there. This is confirmed by our sensitivity simulations with no dissolution above the saturation horizon (Fig. 2). This finding does not depend on the choice of the numerical model, as mixing within the ocean must spread the $\mathrm{TA}^{*}$ signal within the ocean and establish a surface-to-deep gradient in $\mathrm{TA}^{*}$ in the upper ocean even when all $\mathrm{CaCO}_{3}$ dissolves at great depth. The TA* $\mathrm{CFC}$ age method does not account for such processes and assigns dissolution rates in the waters above the saturation horizon irrespective of whether or not the signal stems from the deep ocean. Our approach to combine TA* data within an ocean transport model and the approach by Jin et al. (2006) or Lee (2001) avoid this shortcoming.

In addition, we notice, that in most regions the upper ocean $\mathrm{TA}^{*}$ distribution remains remarkably similar within our ensemble, even for very different dissolution rate profiles (see Fig. 2). Remarkably, for a given export, $k_{\text {slow }}$ dissolution rate profiles, with most of the dissolution at or near the ocean bottom, tend to reach highest values of TA* both in the deep ocean and the thermocline (see also inventories in Table 2). In these cases, most of the TA* source is added to slowly ventilated waters in the deep where it accumulates over time along deep water flow paths. This high $\mathrm{TA}^{*}$ signal is brought to the thermocline and eventually to the surface where $\mathrm{TA}^{*}$ is reset to its preformed value of zero. As a result, a larger 
$\mathrm{TA}^{*}$ gradient is established across the thermocline for deep compared to shallow dissolution. The TA* CFC age method would therefore have a tendency to assign higher dissolution rates in the wrong cases. This further illustrates the difficulty to uniquely relate upper ocean tracer concentrations to either dissolution or mixing processes.

\section{3 $\mathrm{CaCO}_{3}$ dissolution in the deep ocean}

Turning to the deep ocean, Berelson et al. (2007) suggest, based on sediment trap and benthic dissolution data, that the particle flux below $2000 \mathrm{~m}$ is $0.6 \pm 0.3 \mathrm{Gt} \mathrm{Cyr}^{-1}$, sea floor dissolution for sites $>2000 \mathrm{~m}$ averages $0.4 \pm 0.3 \mathrm{Gt}$ $\mathrm{C} \mathrm{yr}^{-1}$, and carbonate burial in deep marine sediments is $0.1 \mathrm{Gt} \mathrm{C} \mathrm{yr}^{-1}$. Our estimate of the particle flux below $1500 \mathrm{~m}$ is $0.52(0.43-0.61) \mathrm{Gt} \mathrm{Cyr}^{-1}$. Thus, the compilation of sediment trap data by Berelson et al. (2007) roughly supports our particle flux at $1500 \mathrm{~m}$. However, the split between sea floor dissolution and open water dissolution in the deep is different. We estimate that most of the deep ocean particle flux dissolves within the water column $(0.40(0.32-0.47) \mathrm{Gt} C$ $\mathrm{yr}^{-1}$ below $1500 \mathrm{~m}$ ). The steady-state burial flux for the runs with interactive sediments is $0.12 \mathrm{Gt} \mathrm{Cyr}^{-1}$, corresponding

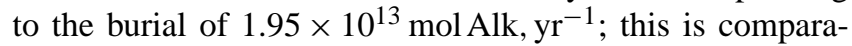
ble in magnitude but smaller than the total alkalinity input by rivers estimated to be $2.3 \times 10^{13} \mathrm{~mol} \mathrm{yr}^{-1}$ by Carter et al. (2014) or the burial flux estimated by Dunne et al. (2012) of $0.121 \mathrm{Gt} \mathrm{Cyr}^{-1}$. We note that $\mathrm{CaCO}_{3}$ formation by coral reefs and burial in shallow coastal waters (Milliman, 1993; Vecsei and Berger, 2004) is not considered in our coarseresolution model.

\subsection{Parameterisations of $\mathrm{CaCO}_{3}$ within Earth system models}

Uncertainties appear too large to objectively determine welldefined parameter ranges for the dissolution rates of calcite and aragonite (judging from both the $\mathrm{TA}^{*}$ and the flux data compilation). A good agreement between simulated and observed $\mathrm{TA}^{*}$ fields can be achieved, irrespective of whether dissolution is assumed to depend on the calcite or aragonite saturation state or whether dissolution rates are assumed to be constant throughout the water column. We recall that the computation of the saturation state by carbonate chemistry routines across all grid cells and for each model time step poses a considerable computational burden. For simplicity, and to minimise computational costs, we therefore recommend describing $\mathrm{CaCO}_{3}$ dissolution by a constant dissolution rate in Earth system models as long as these uncertainties exist. This yields an exponential particle flux profile when assuming constant settling velocities throughout the water column. This approach is used in previous studies (Archer and Maier-Reimer, 1994; Ridgwell et al., 2007). A shortcoming of the application of an exponential particle flux profile for $\mathrm{CaCO}_{3}$ is that it is not easy to account for the potential influ- ence on dissolution of changes in environmental variables, including a decrease in saturation state as expected under ongoing ocean acidification, or in the quality, form, and size distribution of exported $\mathrm{CaCO}_{3}$ particles.

\section{Summary and conclusions}

Constraining the $\mathrm{CaCO}_{3}$ cycle comes down to three fundamental questions: how much $\mathrm{CaCO}_{3}$ is exported from the surface ocean? Where does $\mathrm{CaCO}_{3}$ dissolve in the water column? How much is buried in sediments? Here, we set up a probabilistic framework to constrain the $\mathrm{CaCO}_{3}$ budget within the Bern3D EMIC with observationally based TA* as a robust target variable. The saturation state of water with respect to calcite and aragonite is prescribed using observational estimates to provide realistic boundary conditions for the $\mathrm{CaCO}_{3}$ dissolution parameterisation. In addition to the uncertainty estimates obtained by our Bayesian framework, we also consider uncertainties related to the choice of metrics to define the assimilation target, including flux measurements as an alternative target variable, uncertainties in ocean transport, and ocean-sediment interactions.

We estimate that $0.72-1.05 \mathrm{Gt} \mathrm{C}$ with a best estimate of $0.90 \mathrm{Gt} \mathrm{C}$ are exported out of the surface ocean each year in the form of biogenic $\mathrm{CaCO}_{3}$. Of this, about $37 \%(0.33(0.2-$ $0.4) \mathrm{Gt} \mathrm{yr}^{-1}$ ) is estimated to dissolve in the open water column above $1500 \mathrm{~m}$, and $44 \%\left(0.40(0.32-0.47) \mathrm{Gt} \mathrm{Cyr}^{-1}\right)$ in the open water column below, with the remainder $(0.16$ (0.113-0.23) $\mathrm{Gt} \mathrm{C} \mathrm{yr}^{-1}$ ) deposited on open ocean sediments, globally. Sensitivity simulations with interactive sediments suggest that about $30 \%$ of the deposition flux dissolves back into the ocean and $70 \%$ gets buried in consolidated sediments.

We find that the higher the export fluxes within the constrained, likely ranges, the more likely dissolution above the saturation horizon is needed to distribute $\mathrm{TA}^{*}$ skillfully in the model. Different kinds of dissolution schemes (with and without dissolution above saturation) achieve realistic $\mathrm{TA}^{*}$ distributions within the export ranges identified. Therefore, background dissolution above the saturation horizon cannot be ruled out from this Latin hypercube ensemble evaluated within the Bern3D EMIC. Future progress likely depends on a better observational characterisation of particle concentrations, size distribution, and settling within the water column. Physical transport and mixing reduces concentration gradients such that conceptually different dissolution schemes (e.g. dissolution permitted above saturation or not) cannot be distinguished statistically. This implies that concentrations cannot be used to infer dissolution rates directly. It also implies that dissolution parameterisations remain uncertain. For simplicity and to minimise computational costs, we suggest using saturation-independent parameterisations of $\mathrm{CaCO}_{3}$ dissolution within Earth system models. 


\section{Appendix A: Model evaluation and additional constraints}

It is an essential prerequisite for the model to feature the main water masses and mixing timescales of the ocean to realistically simulate biogeochemical tracers such as $\mathrm{TA}^{*}$. In this Appendix, we graphically document ocean model performance by comparing simulated and observation-based distributions for a range of tracers. Results are for a pre-industrial steady state of the Bern3D ocean model configuration with a horizontal resolution of 40 by 41 grid cells and 32 vertical layers as coupled to an energy balance and sea ice module without the sediment module. The atmospheric history of CFC11 is prescribed according to Bullister (2011). Here we do not account for potential changes in ocean circulation and CFC11 solubility over the industrial period.
Figure A1 provides a Taylor diagram (Taylor, 2001) of CFC $11, \Delta{ }^{14} \mathrm{C}$, temperature, salinity, DIC, TA, $\mathrm{PO}_{4}$, oxygen, and $\mathrm{TA}^{*}$ of the standard model configuration with a constant rain ratio of $7 \%$ and of the median $\mathrm{TA}^{*}$ of the weighted model ensemble. Modelled and observed distributions of the ventilation tracers $\Delta^{14} \mathrm{C}$ and $\mathrm{CFC} 11$ are compared along a section through the Atlantic, Southern Ocean, and Pacific (Figs. A2 and A3). Simulated and observation-based basinmean vertical gradients of $\mathrm{CFC} 11$ and natural $\Delta^{14} \mathrm{C}$ are compared in Fig. A4 for three simulations where diapycnal mixing is set to a low, the standard, and a high value $\left(k_{\mathrm{dia}}=\right.$ $\left.(0.1,0.2,0.5) \times 10^{-4} \mathrm{~m}^{2} \mathrm{~s}^{-1}\right)$. Results bracket observationbased profiles with best agreement between model and observations for the standard set-up. 

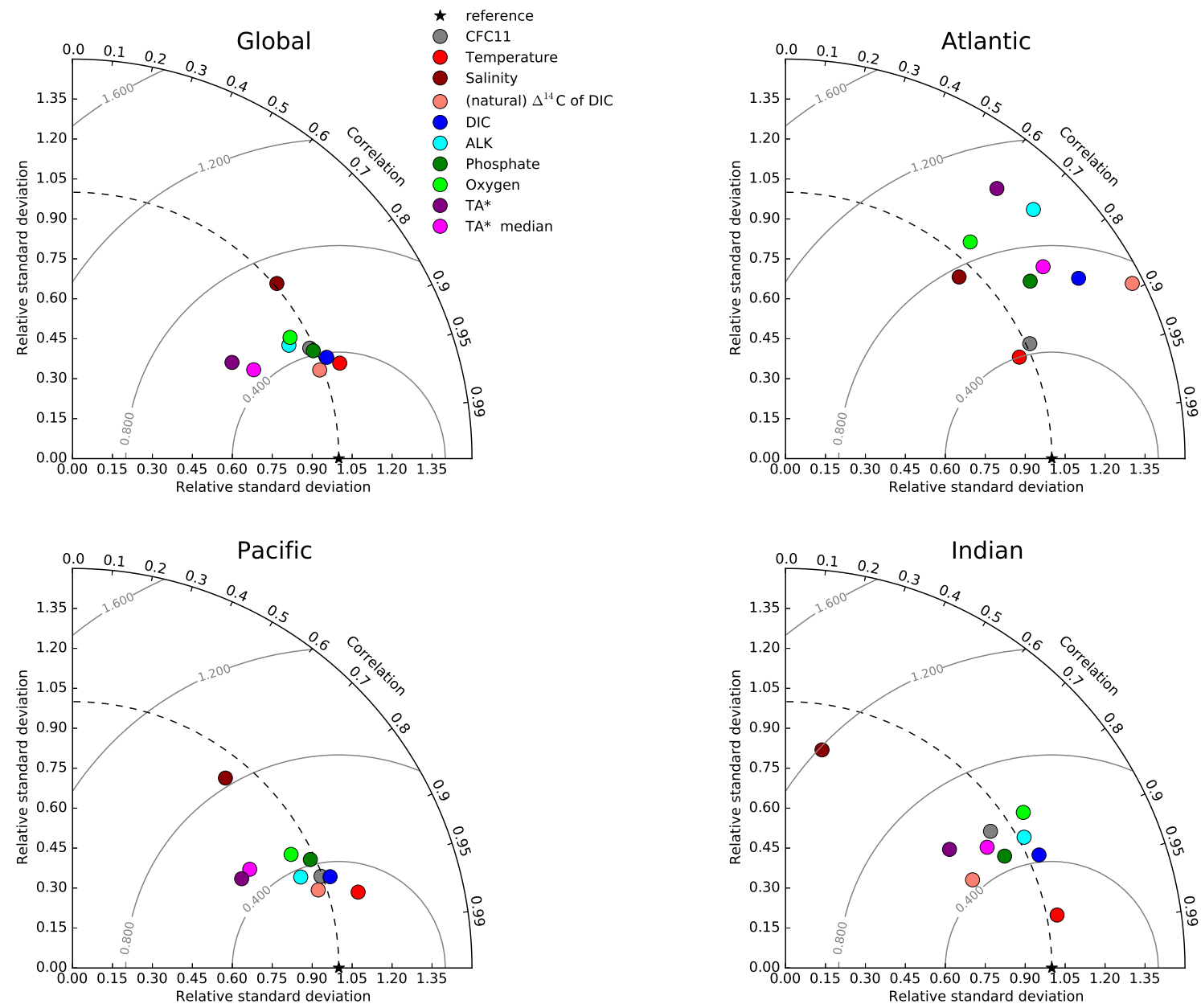

Figure A1. Taylor diagram (Taylor, 2001) for global and basin-wide volume-weighted oceanic tracer distributions as simulated by the Bern3D standard set-up with $k_{\text {dia }}=0.2 \times 10^{-4} \mathrm{~m}^{2} \mathrm{~s}^{-1}$. Observation-derived fields are taken from GLODAP (Key et al., 2004) and the World Ocean Atlas 2009 (Locarnini et al., 2010; Antonov et al., 2010; Garcia et al., 2010a, b). 

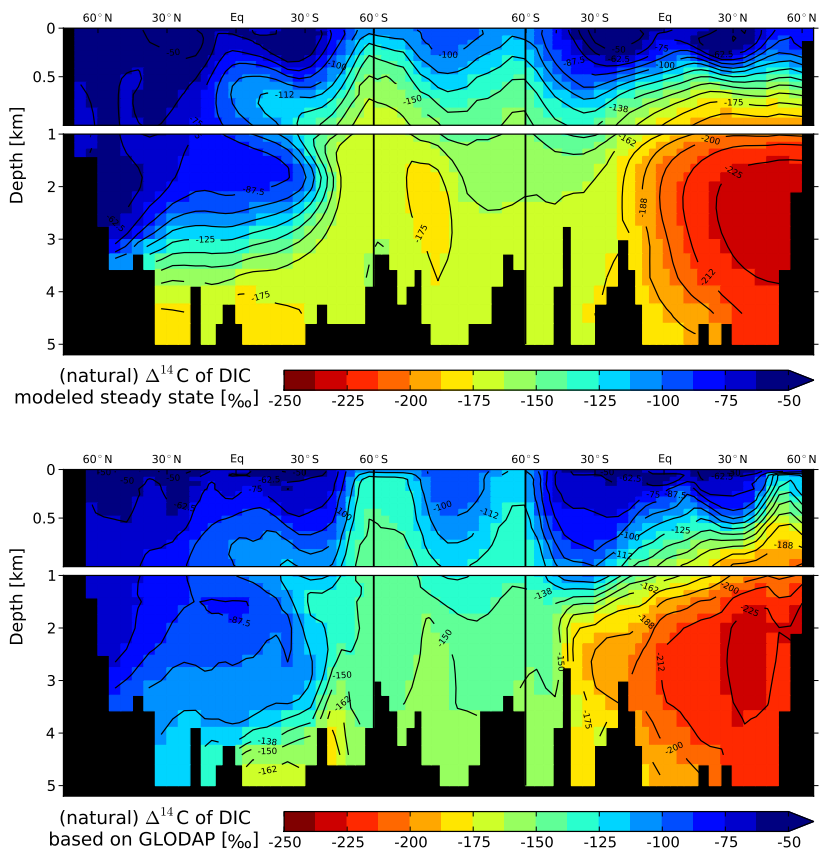

Figure A2. Top: distributions of (natural) $\Delta{ }^{14} \mathrm{C}$ of DIC (\%o) as simulated with a standard $k_{\mathrm{dia}}$ of $0.2 \times 10^{-4} \mathrm{~m}^{2} \mathrm{~s}^{-1}$ at steady state. Bottom: as estimated from $\Delta^{14} \mathrm{C}$ measurements (Key et al., 2004). The correlation coefficient, $\sigma_{\text {rel. }}^{\text {obs. }}$ and RMSEs are $0.89,1.46,23.77 \%$ in the Atlantic; $0.95,0.97,16.28 \%$ in the Pacific; 0.9, 0.78, $21.1 \%$ o in the Indian Ocean. The section displayed is through the Atlantic $\left(25^{\circ} \mathrm{W}\right)$, the Southern Ocean $\left(58^{\circ} \mathrm{S}\right)$, and the Pacific $\left(175^{\circ} \mathrm{W}\right)$.
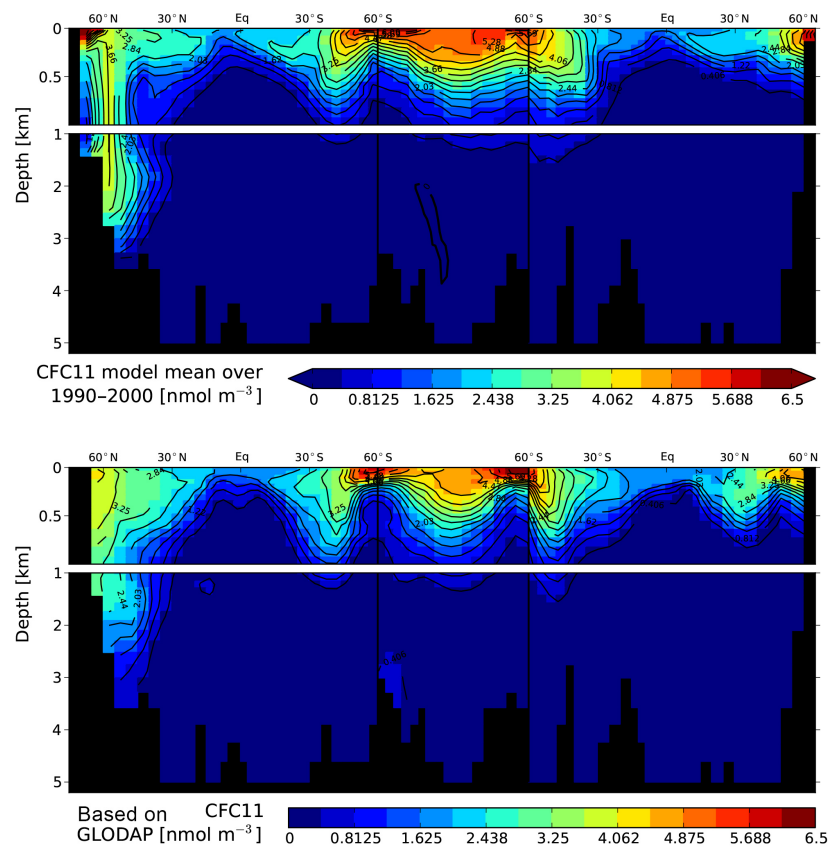

Figure A3. Top: distributions of CFC11 $\left(\mathrm{nmolm}^{-3}\right)$ as simulated with a standard $k_{\text {dia }}$ of $0.2 \times 10^{-4} \mathrm{~m}^{2} \mathrm{~s}^{-1}$ averaged over the model years 1990-2000 and (bottom) as observed (Key et al., 2004). The correlation coefficient, $\sigma_{\text {rel. }}^{\text {obs. }}$ and RMSEs are 0.9, 1.01, $0.45 \mathrm{nmolm}^{-3}$ in the Atlantic; $0.94,1,0.29 \mathrm{nmolm}^{-3}$ in the Pacific; $0.83,0.92,0.54 \mathrm{nmolm}^{-3}$ in the Indian Ocean. The section displayed is through the Atlantic $\left(25^{\circ} \mathrm{W}\right)$, the Southern Ocean $\left(58^{\circ} \mathrm{S}\right)$, and the Pacific $\left(175^{\circ} \mathrm{W}\right)$. 

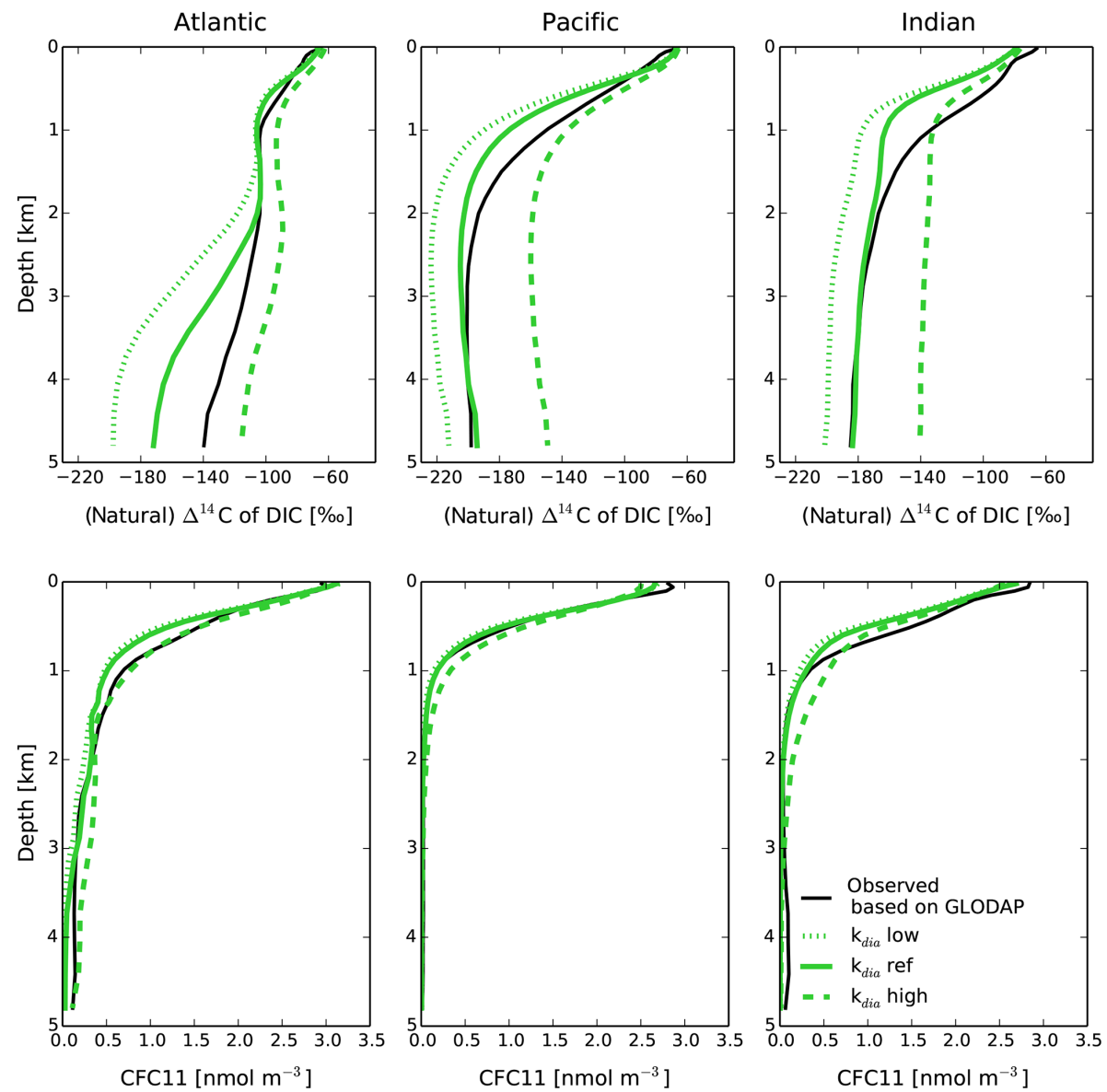

Figure A4. Basin-wide average profiles for (natural) $\Delta^{14} \mathrm{C}$ of DIC (\%o) at steady state (top) and for CFC11 (nmol m ${ }^{-3}$ ) averaged over the model years 1990-2000 (bottom). Results are for simulations with a low (green dotted), standard (green solid), and high (green dashes) value of the diapycnal mixing coefficient $k_{\text {dia }}\left(0.1,0.2\right.$ and $\left.0.5 \times 10^{-4} \mathrm{~m}^{2} \mathrm{~s}^{-1}\right)$. Observation-based estimates are in black. The corresponding Southern Ocean sector is included in the averaging.

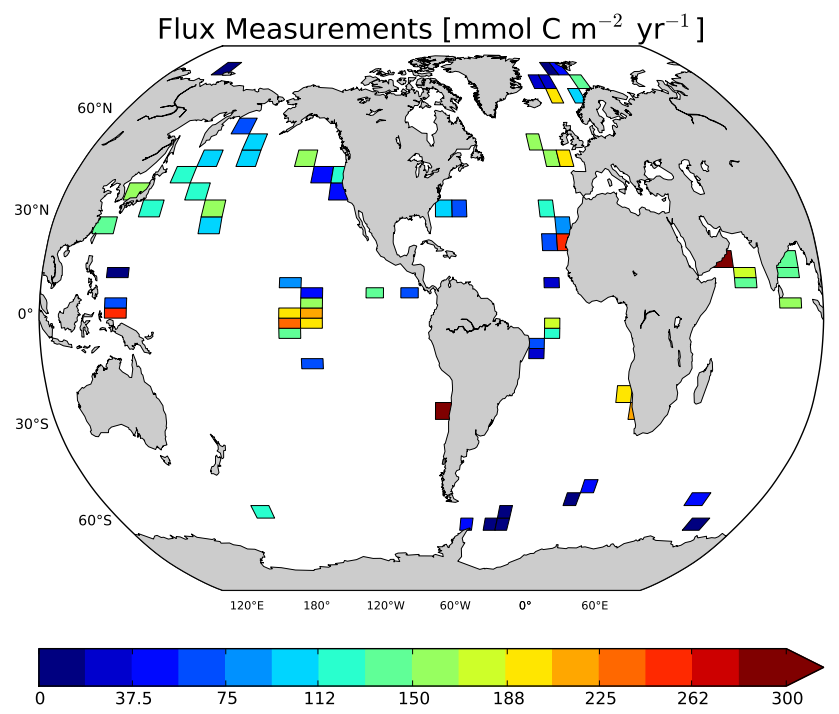

Figure A5. The global sediment trap data collection of Wilson et al. (2012, see their auxiliary material at doi:10.1029/2012GB004398) on the Bern3D grid. The measurements are located at different depths $(>1500 \mathrm{~m})$. If more than one measurement was assigned to the same cell, the mean was chosen. 

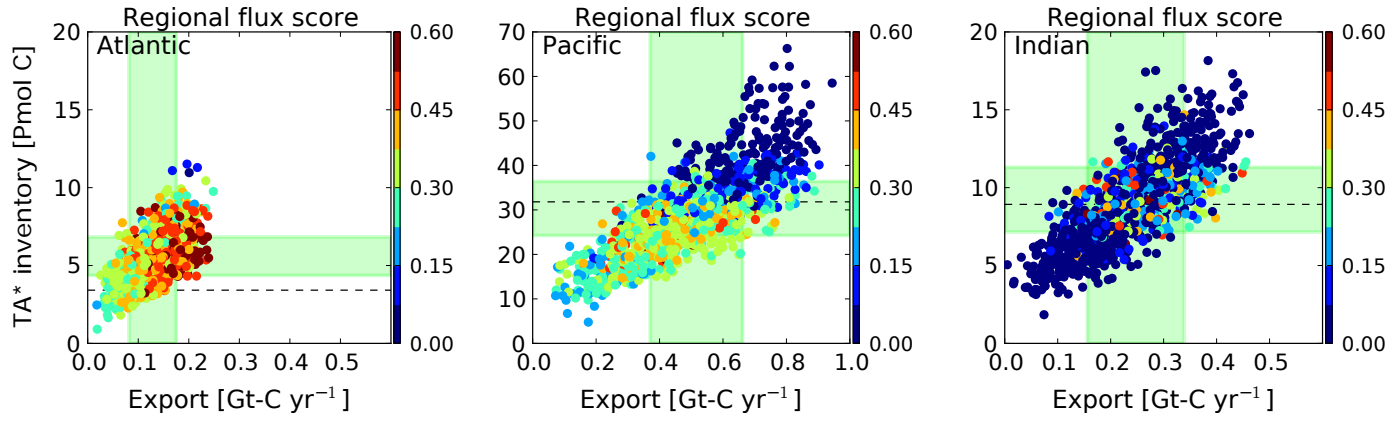

Figure A6. As Fig. 9 but coloured according to model skill with respect to the sediment trap database evaluated by basin. This target variable constrains export and dissolution to wider ranges (yellow to red colours) as compared to the TA* target (light green shading). Generally, high skill scores with respect to regional, sediment-corrected $\mathrm{TA}^{*}$ are also associated with high skill scores with respect to regional fluxes. Only few models are in good agreement with the few flux measurements in the Indian Ocean. 
Acknowledgements. Many thanks to an anonymous reviewer and Wolfgang Koeve for their critical and constructive reviews. Also, thanks to Kitack Lee, Xin Jin, and Niki Gruber for sharing their data, and to Raphael Roth for his contributions to the modelling framework. This work was supported by the Swiss National Science Foundation and the European Project CARBOCHANGE (264879) which received funding from the European Commission's Seventh Framework Programme (FP7/20072013). We acknowledge the support from the International Space Science Institute (ISSI). This publication is an outcome of the ISSI's Working Group on "Carbon Cycle Data Assimilation: How to consistently assimilate multiple data streams".

Edited by: Victor Brovkin

\section{References}

Anderson, L. A. and Sarmiento, J. L.: Redfield ratios of remineralization determined by nutrient data analysis, Global Biogeochem. Cy., 8, 65-80, 1994.

Antonov, J. I., Seidov, D., Boyer, T. P., Locarnini, R. A., Mishonov, A., Garcia, H. E., Baranova, O. K., Zweng, M. M., and Johnson, D. R.: World Ocean Atlas 2009, Volume 2: Salinity, NOAA Atlas NESDIS 69, US Government Printing Office, Washington, D.C., 2010.

Archer, D.: A data-driven model of the global calcite lysocline, Global Biogeochem. Cy., 10, 511-526, doi:10.1029/96GB01521, 1996.

Archer, D. and Maier-Reimer, E.: Effect of deep-sea sedimentary calcite preservation on atmospheric $\mathrm{CO}_{2}$ concentration, Nature, 367, 260-263, doi:10.1038/367260a0, 1994.

Barrett, P. M., Resing, J. A., Buck, N. J., Feely, R. A., Bullister, J. L., Buck, C. S., and Landing, W. M.: Calcium carbonate dissolution in the upper $1000 \mathrm{~m}$ of the eastern North Atlantic, Global Biogeochem. Cy., 28, 386-397, doi:10.1002/2013GB004619, 2014.

Behrenfeld, M. J. and Falkowski, P. G.: Photosynthetic rates derived from satellite-based chlorophyll concentration, Limnol. Oceanogr., 42, 1-20, 1997.

Berelson, W. M., Balch, W. M., Najjar, R., Feely, R. A., Sabine, C., and Lee, K.: Relating estimates of $\mathrm{CaCO} 3$ production, export, and dissolution in the water column to measurements of $\mathrm{CaCO} 3$ rain into sediment traps and dissolution on the sea floor: A revised global carbonate budget, Global Biogeochem. Cy., 21, 1, doi:10.1029/2006GB002803, 2007.

Bishop, J. K. B., Collier, R., Kettens, D., and Edmond, J.: The chemistry, biology, and vertical flux of particulate matter from the upper 1500 m of the Panama Basin, Deep-Sea Res. Pt. I, 27, 615616,1980

Broecker, W. S.: "NO", a conservative water-mass tracer, Earth Planet. Sc. Lett., 23, 100-107, 1974.

Brown, C. W. and Yoder, J. A.: Cocolithophorid blooms in the global ocean, J. Geophys. Res., 99, 7467-7482, 1994.

Bullister, J. L.: Atmospheric CFC-11, CFC-12, CFC-113, CCl4 and SF6 Histories,, Carbon Dioxide Information Analysis Center, Oak Ridge National Laboratory, US Department of Energy, Oak Ridge, Tennessee, available at: http://cdiac.ornl.gov/ftp/oceans/ CFC_ATM_Hist/ (last access: 3 April 2012), 2011.
Carr, M.-E.: Estimation of potential productivity in Eastern Boundary Currents using remote sensing, Deep-Sea Res. Pt. II, 49, 5980, 2002.

Carter, B. R., Toggweiler, J. R., Key, R. M., and Sarmiento, J. L.: Processes determining the marine alkalinity and calcium carbonate saturation state distributions, Biogeosciences, 11, 73497362, doi:10.5194/bg-11-7349-2014, 2014.

Chung, S.-N., Lee, K., Feely, R. A., Sabine, C. L., Millero, F. J., Wanninkhof, R., Bullister, J. L., Key, R. M., and Peng, T.-H.: Calcium carbonate budget in the Atlantic Ocean based on water column inorganic carbon chemistry, Global Biogeochem. Cy., 17, 4, doi:10.1029/2002GB002001, 2003.

Doney, S. C., Lindsay, K., Fung, I., and John, J.: Natural Variability in a Stable, 1000-yr Global Coupled Climate-Carbon Cycle Simulation, J. Climate, 19, 3033-3054, doi:10.1175/JCLI3783.1, 2006.

Dunne, J. P., Armstrong, R. A., Gnanadesikan, A., and Sarmiento, J. L.: Empirical and mechanistic models for the particle export ratio, Global Biogeochem. Cy., 19, 1-16, doi:10.1029/2004GB002390, 2005.

Dunne, J. P., Hales, B., and Toggweiler, J. R.: Global calcite cycling constrained by sediment preservation controls, Global Biogeochem. Cy., 26, GB3023, doi:10.1029/2010GB003935, 2012.

Duteil, O., Koeve, W., Oschlies, A., Bianchi, D., Galbraith, E., Kriest, I., and Matear, R.: A novel estimate of ocean oxygen utilisation points to a reduced rate of respiration in the ocean interior, Biogeosciences, 10, 7723-7738, doi:10.5194/bg-10-7723-2013, 2013.

Edwards, N. R., Willmott, A. J., and Killworth, P. D.: On the Role of Topography and Wind Stress on the Stability of the Thermohaline Circulation, J. Phys. Oceanogr., 28, 756-778, 1998.

Feely, R. A., Sabine, C. L., Lee, K., Millero, F. J., Lamb, M. F., Greeley, D., Bullister, J. L., Key, R. M., Peng, T.-H., Kozyr, A., Ono, T., and Wong, C. S.: In situ calcium carbonate dissolution in the Pacific Ocean, Global Biogeochem. Cy., 16, 12-91, doi:10.1029/2002GB001866, 2002.

Feely, R. A., Sabine, C. L., Lee, K., Berelson, W., Kleypas, J., Fabry, V. J., and Millero, F. J.: Impact of anthropogenic $\mathrm{CO}_{2}$ on the $\mathrm{CaCO}_{3}$ system in the oceans, Science, 305, 362-6, doi:10.1126/science.1097329, 2004.

Francois, R., Honjo, S., Krishfield, R., and Manganini, S.: Factors controlling the flux of organic carbon to the bathypelagic zone of the ocean, Global Biogeochem. Cy., 16, 34-1-34-20, doi:10.1029/2001GB001722, 2002.

Friis, K., Najjar, R. G., Follows, M. J., and Dutkiewicz, S.: Possible overestimation of shallow-depth calcium carbonate dissolution in the ocean, Global Biogeochem. Cy., 20, 4, doi:10.1029/2006GB002727, 2006.

Gangst $\varnothing$, R., Joos, F., and Gehlen, M.: Sensitivity of pelagic calcification to ocean acidification, Biogeosciences, 8, 433-458, doi:10.5194/bg-8-433-2011, 2011.

Garcia, H. E., Locarnini, R. A., Boyer, T. P., Antonov, J. I., Baranova, O. K., Zweng, M. M., and Johnson, D. R.: World Ocean Atlas 2009, Volume 3: Dissolved Oxygen, Apparent Oxygen Utilization, and Oxygen Saturation, NOAA Atlas NESDIS 70, US Government Printing Office, Washington, D.C., 2010a.

Garcia, H. E., Locarnini, R. A., Boyer, T. P., Antonov, J. I., K, Z. M., Zweng, M. M., Baranova, O., Johnson, D. R., Seidov, D., Mishonov, A., and Johnson, D. R.: World Ocean Atlas 2009, Volume 
4: Nutrients (phosphate, nitrate, silicate) Utilization, and Oxygen Saturation, NOAA Atlas NESDIS, U.S. Government Printing Office, Washington, D.C., 2010b.

Gattuso, J., Epitalon, J., Lavigne, H., Orr, J., Gentili, B., Hofmann, A., Proye, A., Soetaert, K., and Rae, J.: seacarb: Seawater Carbonate Chemistry, available at: http://CRAN.R-project.org/ package $=$ seacarb (last access: 29 August 2012), 2010.

Gehlen, M., Bopp, L., Emprin, N., Aumont, O., Heinze, C., and Ragueneau, O.: Reconciling surface ocean productivity, export fluxes and sediment composition in a global biogeochemical ocean model, Biogeosciences, 3, 521-537, doi:10.5194/bg-3521-2006, 2006.

Griffies, S. M.: The Gent-McWilliams Skew Flux, J. Phys. Oceanogr., 28, 831-841, 1998.

Gruber, N., Sarmiento, J. L., and Stocker, T. F.: An improved method for detecting anthropogenic $\mathrm{CO} 2$ in the oceans, Global Biogeochem. Cy., 10, 809-837, doi:10.1029/96GB01608, 1996.

Heinze, C.: Simulating oceanic $\mathrm{CaCO}_{3}$ export production in the greenhouse, Geophys. Res. Lett., 31, L16308, doi:10.1029/2004GL020613, 2004.

Heinze, C., Maier-Reimer, E., Winguth, A. M. E., and Archer, D.: A global oceanic sediment model for long-term climate studies, Global Biogeochem. Cy., 13, 221-250, 1999.

Honjo, S., Manganini, S. J., Krishfield, R. A., and Francois, R.: Particulate organic carbon fluxes to the ocean interior and factors controlling the biological pump: A synthesis of global sediment trap programs since 1983, Prog. Oceanogr., 76, 217-285, doi:10.1016/j.pocean.2007.11.003, 2008.

Ito, T., Follows, M. J., and Boyle, E. A.: Is AOU a good measure of respiration in the ocean?, Geophys. Res. Lett., 31, 17, doi:10.1029/2004GL020900, 2004.

Jansen, H. and Wolf-Gladrow, D. A.: Carbonate dissolution in copepod guts: A numerical model, Mar. Ecol.-Prog. Ser., 221, 199207, 2001

Jansen, H., Zeebe, R. E., and Wolf-Gladrow, D. A.: Modeling the dissolution of settling $\mathrm{CaCO} 3$ in the ocean, Global Biogeochem. Cy., 16, 11-1-11-16, doi:10.1029/2000GB001279, 2002.

Jin, X., Gruber, N., Dunne, J. P., Sarmiento, J. L., and Armstrong, R. A.: Diagnosing the contribution of phytoplankton functional groups to the production and export of particulate organic carbon, $\mathrm{CaCO} 3$, and opal from global nutrient and alkalinity distributions, Global Biogeochem. Cy., 20, 1-17, doi:10.1029/2005GB002532, 2006.

Kalnay, E., Kanamitsu, M., Kistler, R., Collins, W., Deaven, D., Gandin, L., Iredell, M., Saha, S., White, G., Woollen, J., Zhu, Y., Chelliah, M., Ebisuzaki, W., Higgins, W., Janowiak, J., Mo, K. C., Ropelewski, C., Wang, J., Leetmaa, A., Reynolds, R., Jenne, R., and Joseph, D.: The NCEP/NCAR 40-year reanalysis project, B. Am. Meteorol. Soc., 77, 437-471, 1996.

Kanamori, S. and Ikegami, H.: Calcium-alkalinity relationship in the North Pacific, J. Oceanogr. Soc. Jpn, 38, 57-62, 1982.

Key, R. M., Kozyr, A., Sabine, C. L., Lee, K., Wanninkhof, R., Bullister, J. L., Feely, R. A., Millero, F. J., Mordy, C., and Peng, T.-H.: A global ocean carbon climatology: Results from Global Data Analysis Project (GLODAP), Global Biogeochem. Cy., 18, GB4031, doi:10.1029/2004GB002247, 2004.

Koeve, W., Duteil, O., Oschlies, A., Kähler, P., and Segschneider, J.: Methods to evaluate $\mathrm{CaCO}_{3}$ cycle modules in coupled global biogeochemical ocean models, Geosci. Model Dev., 7, 23932408, doi:10.5194/gmd-7-2393-2014, 2014.

Lee, K.: Global net community production estimated from the annual cycle of surface water total dissolved inorganic carbon, Limnol. Oceanogr., 46, 1287-1297, 2001.

Locarnini, R. A., Mishonov, A., Antonov, J. I., Boyer, T. P., Garcia, H. E., Baranova, O. K., Zweng, M. M., and Johnson, D. R.: World Ocean Atlas 2009, Volume 1: Temperature, Tech. rep., US Government Printing Office, Washington, D.C., 2010.

Marra, J., Ho, C., and Trees, C. C.: An algorithm for the calculation of primary production from remote sensing data, LamontDoherty Earth Obs., Palisades, NY, 2003.

McKay, M. D., Beckman, R. J., and Conover, W. J.: A comparison of three methods for selecting values of input variables in the analysis of output from a computer code, Technometrics, 21, 239-245, 1979.

Milliman, J. D.: Production and accumulation of calcium carbonate in the ocean: Budget of a nonsteady state, Global Biogeochem. Cy., 7, 927-957, doi:10.1029/93GB02524, 1993.

Milliman, J. D., Troy, P. J., Balch, W. M., Adams, A. K., Li, Y. H., and Mackenzie, F. T.: Biologically mediated dissolution of calcium carbonate above the chemical lysocline?, Deep-Sea Res. Pt I, 46, 1653-1669, doi:10.1016/S0967-0637(99)00034-5, 1999.

Mucci, A.: The solubility of calcite and aragonite in seawater at various salinities, temperatures, and one atmosphere total pressure, Am. J. Sci., 283, 780-799, 1983.

Müller, S. A., Joos, F., Edwards, N. R., and Stocker, T. F.: Water mass distribution and ventilation time scales in a cost-efficient, three-dimensional ocean model, J. Climate, 19, 5479-5499, doi:10.1175/JCLI3911.1, 2006.

Müller, S. A., Joos, F., Edwards, N. R., and Stocker, T. F.: Modeled natural and excess radiocarbon: Sensitivities to the gas exchange formulation and ocean transport strength, Global Biogeochem. Cy., 22, 3, doi:10.1029/2007GB003065, 2008.

Najjar, R. G., Orr, J., Sabine, C. L., and Joos, F.: Biotic-HOWTO. Internal OCMIP Report, Tech. rep., LSCE/CEA Saclay, Gif-surYvette, France, 1999.

Orr, J. and Najjar, R. G.: Abiotic-HOWTO. Internal OCMIP Report, Tech. rep., LSCE/CEA Saclay, Gif-sur-Yvette, France, 1999.

Parekh, P., Joos, F., and Müller, S. A.: A modeling assessment of the interplay between aeolian iron fluxes and ironbinding ligands in controlling carbon dioxide fluctuations during Antarctic warm events, Paleoceanography, 23, PA4202, doi:10.1029/2007PA001531, 2008.

Ridgwell, A., Hargreaves, J. C., Edwards, N. R., Annan, J. D., Lenton, T. M., Marsh, R., Yool, A., and Watson, A.: Marine geochemical data assimilation in an efficient Earth System Model of global biogeochemical cycling, Biogeosciences, 4, 87-104, doi:10.5194/bg-4-87-2007, 2007.

Ritz, S. P., Stocker, T. F., and Severinghaus, J. P.: Noble gases as proxies of mean ocean temperature: sensitivity studies using a climate model of reduced complexity, Quaternary Sci. Rev., 30, 3728-3741, doi:10.1016/j.quascirev.2011.09.021, 2011.

Roth, R., Ritz, S. P., and Joos, F.: Burial-nutrient feedbacks amplify the sensitivity of atmospheric carbon dioxide to changes in organic matter remineralisation, Earth Syst. Dynam., 5, 321-343, doi:10.5194/esd-5-321-2014, 2014.

Sabine, C. L., Feely, R. A., Key, R. M., Bullister, J. L., Millero, F. J., Lee, K., Peng, T.-H., Tilbrook, B., Ono, T., and Wong, C. S.: Dis- 
tribution of anthropogenic $\mathrm{CO}_{2}$ in the Pacific Ocean, Global Biogeochem. Cy., 16, 17-30, doi:10.1029/2001GB001639, 2002a.

Sabine, C. L., Key, R. M., Feely, R. A., and Greeley, D.: Inorganic carbon in the Indian Ocean: distribution and dissolution processes, Global Biogeochem. Cy., 16, 4, doi:10.1029/2002GB001869, 2002b.

Sarmiento, J. L. and Gruber, N.: Ocean biogeochemical dynamics, Princeton University Press, 2006.

Sarmiento, J. L., Dunne, J., Gnanadesikan, A., Key, R. M., Matsumoto, K., and Slater, R.: A new estimate of the $\mathrm{CaCO} 3$ to organic carbon export ratio, Global Biogeochem. Cy., 16, 54-154-12, doi:10.1029/2002GB001919, 2002.

Schmittner, A., Urban, N. M., Keller, K., and Matthews, D.: Using tracer observations to reduce the uncertainty of ocean diapycnal mixing and climate-carbon cycle projections, Global Biogeochem. Cy., 23, 1-16, doi:10.1029/2008GB003421, 2009.

Steinacher, M. and Joos, F.: Transient Earth system responses to cumulative carbon dioxide emissions: linearities, uncertainties, and probabilities in an observation-constrained model ensemble, Biogeosciences, 13, 1071-1103, doi:10.5194/bg-13-1071-2016, 2016.

Steinacher, M., Joos, F., Frölicher, T. L., Bopp, L., Cadule, P., Cocco, V., Doney, S. C., Gehlen, M., Lindsay, K., Moore, J. K., Schneider, B., and Segschneider, J.: Projected 21 st century decrease in marine productivity: a multi-model analysis, Biogeosciences, 7, 979-1005, doi:10.5194/bg-7-979-2010, 2010.

Steinacher, M., Joos, F., and Stocker, T. F.: Allowable carbon emissions lowered by multiple climate targets, Nature, 499, 197-201, doi:10.1038/nature12269, 2013.
Taylor, K. E.: Summarizing multiple aspects of model performance in a single diagram, J. Geophys. Res., 106, D7, doi:10.1029/2000JD900719, 2001.

Tschumi, T., Joos, F., Gehlen, M., and Heinze, C.: Deep ocean ventilation, carbon isotopes, marine sedimentation and the deglacial $\mathrm{CO}_{2}$ rise, Clim. Past, 7, 771-800, doi:10.5194/cp-7-771-2011, 2011.

Vecsei, A. and Berger, W. H.: Increase of atmospheric $\mathrm{CO}_{2}$ during deglaciation: Constraints on the coral reef hypothesis from patterns of deposition, Global Biogeochem. Cy., 18, GB1035, doi:10.1029/2003GB002147, 2004.

Volk, T. and Hoffert, M. I.: Ocean carbon pumps: Analysis of relative strengths and efficiencies in ocean-driven atmospheric $\mathrm{CO}_{2}$ changes, The Carbon Cycle and Atmospheric CO: Natural Variations Archean to Present, 99-110, 1985.

Wilson, J. D., Barker, S., and Ridgwell, A.: Assessment of the spatial variability in particulate organic matter and mineral sinking fluxes in the ocean interior: Implications for the ballast hypothesis, Global Biogeochem. Cy., 26, 4, doi:10.1029/2012GB004398, 2012.

Wolf-Gladrow, D. A., Zeebe, R. E., Klaas, C., Körtzinger, A., and Dickson, A. G.: Total alkalinity: The explicit conservative expression and its application to biogeochemical processes, Mar. Chem., 106, 287-300, doi:10.1016/j.marchem.2007.01.006, 2007. 